\title{
Einstein, Michelson, and the "Crucial" Experiment
}

\section{Citation}

Holton, Gerald. 1969. Einstein, Michelson, and the "Crucial" Experiment. Isis 60 (2) (Summer, 1969): 132-197.

\section{Published Version}

https://www.jstor.org/stable/229907

\section{Permanent link}

http://nrs.harvard.edu/urn-3:HUL.InstRepos:37902463

\section{Terms of Use}

This article was downloaded from Harvard University's DASH repository, and is made available under the terms and conditions applicable to Other Posted Material, as set forth at http:// nrs.harvard.edu/urn-3:HUL.InstRepos:dash.current.terms-of-use\#LAA

\section{Share Your Story}

The Harvard community has made this article openly available.

Please share how this access benefits you. Submit a story.

\section{Accessibility}




\title{
Einstein, Michelson, and the "Crucial" Experiment
}

\author{
By Gerald Holton*
}

\section{INTRODUCTION}

THE HIGHEST ACHIEVEMENTS in science are of quite different kinds: I the bold theoretical generalization, breathtaking by virtue of its sweeping synthetic power, and the ingenious experiment, sometimes called "crucial," in which the striking character of the result signals a turning point. Albert Einstein's special theory of relativity as first published in 1905 is a supreme example of the first kind, and A. A. Michelson's experiments in the 1880's to find the effect of ether drift on the speed of light are often cited as prototypical examples of the second kind. Even if these two achievements had nothing whatsoever to do with each other, each would continue to be remembered and studied on its own merit. But these two cases have in fact held additional interest for historians and philosophers of science; for, as we shall see, it has been the overwhelming preponderance of opinion over the last half century that Michelson's experiments and Einstein's theory have a close genetic connection, one which may be stated most simply in the words of the caption under Michelson's photograph in a recent publication of a scientific society (see frontispiece): Michelson "made the measurements on which are based Einstein's Special Theory of Relativity."

A more detailed account of the experimental origins of relativity theory is attempted in R. A. Millikan's essay "Albert Einstein on his Seventieth Birthday." It was the lead article in a special issue in Einstein's honor of the Reviews of Modern Physics, and the early parts are worth quoting:

The special theory of relativity may be looked upon as starting essentially in a generalization from Michelson's experiment. And here is where Einstein's characteristic boldness of approach came in, for the distinguishing feature of modern scientific thought lies in the fact that it begins by discarding all $a$ priori conceptions about the nature of reality - or about the ultimate nature of the universesuch as had characterized practically all Greek philosophy and all medieval thinking as well, and takes instead, as its starting point, well-authenticated, care-

* Jefferson Physics Laboratory, Harvard University. I thank the Executor and Trustees of the Albert Einstein Estate, and particularly Miss Helen Dukas, for help and for permission to cite from the publications and documents of Einstein. Early versions of the paper were discussed in my History of Science seminar, and a draft was presented as one of the Monday Lectures at the University of Chicago, November 1967. I am also grateful for the opportunity which the Rockefeller Foundation and the Director of the Villa Serbelloni provided to write up the final draft. 


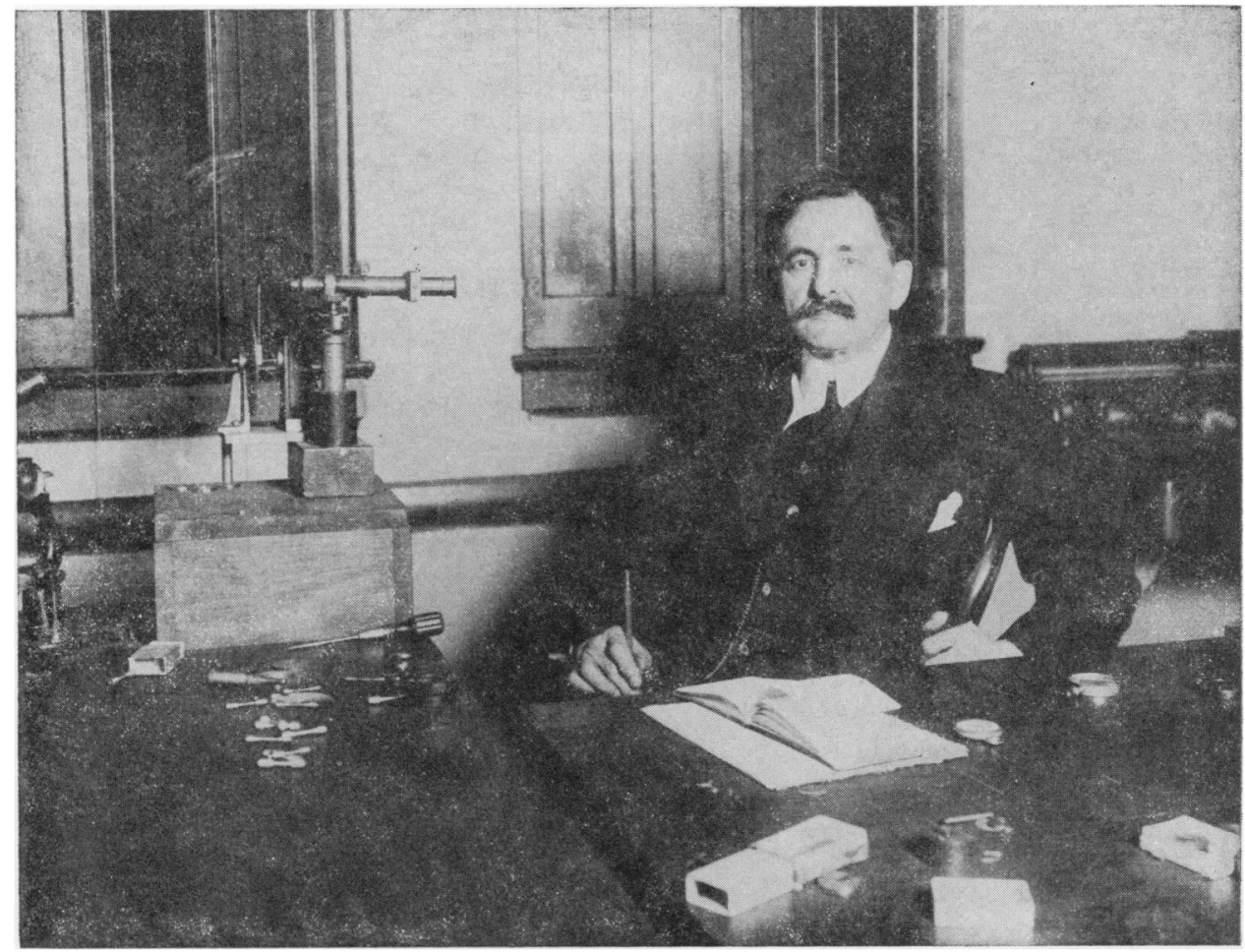

"Albert Abraham Michelson, first American scientist to win the Nobel prize in physics, made the measurements on which are based Einstein's Special Theory of Relativity. Michelson is shown here in his laboratory at the University of Chicago." Photograph and caption as published in Your Career in Optics (New York: Optical Society of America, 1965), p. 3. Reproduced by permission. 
fully tested experimental facts, no matter whether these facts seem at the moment to be reasonable or not. In a word, modern science is essentially empirical. . . .

But this experiment, after it had been performed with such extraordinary skill and refinement by Michelson and Morley, yielded with great definiteness the answer that there is ... no observable velocity of the earth with respect to the aether. That unreasonable, apparently inexplicable experimental fact was very bothersome to 19th century physics, and so for almost twenty years after this fact came to light physicists wandered in the wilderness in the disheartening effort to make it seem reasonable. Then Einstein called out to us all, "Let us merely accept this as an established experimental fact and from there proceed to work out its inevitable consequences," and he went at that task himself with an energy and a capacity which very few people on earth possess. Thus was born the special theory of relativity. ${ }^{1}$

The birth of a new theory as the response to a puzzling empirical finding! This sort of thing has happened; but it may also be the stuff of which fairy tales are made. The historian of science senses at once several intriguing problems: How important were experiments to Einstein's formulation of his 1905 paper on relativity? What role did the Michelson experiments play? How good is the evidence on which one is to decide these questions? What light do documents shed on the case, particularly those that appear to provide contradictory evidence? If the Michelson experiments were not of crucial importance, why are there so many who say they were? And if they were, why are there a few who say they were not? What are the philosophical (or other) assumptions made by these two groups? What can this case tell us about the relation between experiment and theory in modern physics? And above all, what can this case tell us about the rival claims of sensationism and idealism to represent more faithfully the act of modern scientific innovation?

Thus what appears at first to be a limited case opens into the wider field of current scholarship—not the kind of history that uses a wide-angle lens to compose a picture of the rise and fall of major theories, but a case study that focuses a magnifying glass in order to understand a part of modern scientific work. We shall see that there is so much to be observed, so many documents and personae, that even in a full-length essay all the questions cannot be disposed of. Instead, I shall concentrate on those that are particularly illuminated by documents, including some newly found and unpublished ones, and I shall also take the opportunity to gather together and compare previous contributions to this topic that are still widely dispersed.

Partly because of the volume of the resources, many will appear contradictory or ambiguous. Einstein himself made different statements about the influence of the Michelson experiments, ranging from "there is no doubt that Michelson's experiment was of considerable influence on my work ..." to "the MichelsonMorley experiment had a negligible effect on the discovery of relativity." The initial apparent irreconcilability of the statements need not cause dismay. On the contrary: It is no more comforting to find only unambiguous evidence for

1 R. A. Millikan, "Albert Einstein on his Seventieth Birthday," Reviews of Modern

Physics, 1949, 21: 343-344; italics in original. 
one position on a complex issue, for that may indicate that only part of the evidence is in.

Our job will be to weigh incommensurables. And in this act we must try to discern the conceptual framework, motivation, or social mission hiding behind a statement that is asserting to be evidence. Historical statements, like those in physics, have meaning only relative to a specifiable framework. The discovery of the contextual setting will sometimes be as interesting as the use to which a "relativistic" piece of evidence can be put, and thus the light thrown on a specialized problem may help to illuminate a chapter in the history of ideas.

A different purpose of such a study might be simply the correction of popular error. Though it is tempting, this is not my chief aim; nor is it likely to be successful. For the belief that Einstein based his work leading to his 1905 publication of relativity theory on Michelson's result has long been a part of the folklore. It is generally regarded as an important event in the history of science, as widely known and believed as the story of the falling apple in Newton's garden and of the two weights dropped from the leaning tower in Galileo's Pisa - two other cases in which experiential fact is supposed to have provided the genesis of synthetic theory. If Millikan's report and the many others like it are right, then this might be the time when one can still hope to find reliable evidence for them. But if they are not supportable, it is probably in any case too late to stop the spread of a fable which has such inherent appeal.

\section{The Symbiosis of Puzzles}

At least a brief summary of the essential points of the familiar Michelson experiment may be useful here, even though this will not convey one of the major reasons why it has proved irresistible for so many physics books to give a place of importance to this particular experiment-the fact that it was one of the most fascinating in the history of physics. Its fascination, which has been felt equally by textbook writers and research physicists, derives from its beauty and mystery. Despite the central position of the question of ether drift in late-nineteenthcentury physics, nobody before Michelson was able to imagine and construct an apparatus to measure the second-order effect of the presumed ether drift. The interferometer was a lovely thing. Invented by the twenty-eight-year-old Michelson in response to a challenge by Maxwell, it was capable of revealing an effect of the order of one part in ten billion. It is to this day one of the most precise instruments in science, and the experiment is one that carried precision to the extreme limits. Einstein himself later paid warm and sincere tribute to Michelson's experimental genius and artistic sense. ${ }^{2}$

2 Quoted in R. S. Shankland, "Conversations with Albert Einstein," American Journal of Physics, 1963, 31: 47-57. From time to time, current research papers in physics come back to the Michelson experiment to view it in a new light; e.g., P. P. Phillips, "Is the Graviton a Goldstone Boson?" Physical Review, 1966, 146: 966.

It should be noted that in this paper, as in most of the physics literature, the term "Michelson experiment" is used more or less interchangeably with "Michelson experiments," "Michelson-Morley experiments," etc. A useful summary of the whole sequence of closely related experiments by Michelson (1881), by Michelson together with his colleague E. Morley (publ. 1887), by Morley and D. C. Miller (1902-1904), etc., will be 
As Michelson recounts in his description of his experiment (in Studies in Optics, 1927), among the events that led up to it was first of all George B. Airy's experiment on the angle of aberration of a telescope viewing a star from our moving earth. On the model of light as wave propagation through an ether, the aberration angle was expected to be larger when the observing telescope was filled with water; but on experiment the angle was found to be the same. Augustin Fresnel therefore proposed that the ether is partly carried or dragged along in the motion of a medium (such as water) having a refractive index larger than 1. This hypothesis, in quantitative detail, interpreted Airy's result in a satisfying way and was triumphantly tested in a separate experiment by Armand Fizeau on the effect of moving water on the propagation of a light beam as measured in the laboratory frame of reference. At the same time the experiment implied that a medium of refractive index 1 (such as air) would, when in motion, not carry along any part of the ether.

The hypothesis that the earth moves through an ether which remains unaffected and stagnant all around the earth (later most prominently developed by H. A. Lorentz) invited direct experimental verification. But that required the previously unimaginable feat of looking for the exceedingly small presumed effect of the second order, for the relative earth-ether motion ("ether drift") would show up in a change of the effective light speed by a factor containing the square of the ratio of the speeds of the earth and of light $\left(v^{2} / c^{2}=10^{-8}\right)$.

Michelson's ingenious solution was to let two light beams from the same source simultaneously run a round-trip race along two paths which had effectively the same length in the laboratory but were laid out at 90 degrees, thereby causing the two light beams to be differently affected by their relative motion with respect to the ether. But on bringing the two beams together to compare by their interference pattern these relative effects, Michelson's apparatus (an "interferometer") surprisingly gave what is usually called a negative or null result. More accurately, it gave within experimental error the result that would have been expected on the basis of a quite different hypothesis-namely, that the ether is not stagnant but somehow does get dragged along with the earth and so has no measurable motion or drift with respect to the earth.

The beauty of the design and execution of the experiment was in startling contrast to the mysterious difficulties which attended its interpretation. On one level lay the problem of a detailed understanding of the way the apparatus worked in the context of ether theory, regardless of the meaning of the results. Michelson himself, on presenting in 1882 an account of his first experiment to the Académie des Sciences, acknowledged that he had made an error in his earlier report of 1881 and had neglected the effect of the earth's motion on the path of light in the interferometer arm at right angles to the motion. A. Potier, who had pointed out the error to Michelson in 1882, was in error also. ${ }^{3}$ On another point

found in R. S. Shankland et al., “A New Analysis of the Interferometer Observations of Dayton C. Miller," Rev. Mod. Phys., 1955, 27: $167 \mathrm{ff} . ; \mathrm{T}$. W. Chalmers, Historic Researches (London: Morgan Brothers, 1949); and most compactly in W. K. H. Panofsky and M. Phillips, Classical Electricity and Magnetism (Reading, Mass.: Addison-Wesley, 1956), p. 235.

3 R. S. Shankland, "The Michelson-Morley 
-how the moving reflectors in the interferometer affect the angle of reflectionthere was a continuing debate for over thirty years. To appreciate the lasting confusion one need only study the record of the summit conference of ether-drift experimenters, held 4-5 February 1927, at the Mt. Wilson Observatory, under the title "Conference on the Michelson-Morley Experiment," with both Michelson and Lorentz in attendance. ${ }^{4}$ Although one finds today many simplified accounts of the experiment, in fact a detailed, correct theory of the supposed working of the Michelson interferometer to detect an ether drift is quite complex and is rarely given in full.

But beyond that, on another level the outcome itself was enormously puzzling to everyone at the time, and to many for a long time afterward. The glorious device had yielded a disappointing, even incomprehensible, result in the context of the then-current theory. Michelson himself called his experiment a "failure,"5 the repeatedly obtained null or nearly null results being contrary to all expectations. Unlike the stereotype of the true scientist who accepts the experimental test that falsifies a theory, he refused to grant the importance of his result, saying, "Since the result of the original experiment was negative, the problem is still demanding a solution."6 $\mathrm{He}$ even tried to console himself with the remarkable observation that "the experiment is to me historically rich because it was for the solution of this problem that the interferometer was devised. I think it will be admitted that the problem, by leading to the invention of the interferometer, more than compensated for the fact that this particular experiment gave a negative result."7

Others were just as mystified and displeased. Lorentz wrote to Rayleigh on 18 August 1892: "I am utterly at a loss to clear away this contradiction, and yet I believe if we were to abandon Fresnel theory [of the ether], we should have no adequate theory at all. . . Can there be some point in the theory of $\mathrm{Mr}$. Michelson's experiment which has as yet been overlooked?"8 Lord Kelvin, who had discerned the result of the experiment as part of a cloud obscuring "the beauty and clearness of the dynamical theory, which asserts heat and light to be modes of motion," could not, even into the 1900's, reconcile himself to the negative findings. ${ }^{9}$ Rayleigh, who, like Kelvin, had encouraged Michelson to repeat his first experiment, found the null result obtained by Michelson and Morley to be "a real disappointment."10 As Loyd S. Swenson has pointed out, ${ }^{11}$ Michel-

Experiment," Am. J. Phys., 1964, 32: 23. In 1886 (Neederland Archives, 1886, 21: 104176), Lorentz showed also that Michelson's analysis in 1882 of the action of the interferometer was in error, i.e., that it predicted double the expected fringe shift.

4 "Conference on the Michelson-Morley Experiment," Astrophysical Journal, 1928, 68: 341.

5 Bernard Jaffe, Michelson and the Speed of Light (New York: Doubleday, 1960), p. 89.

6 Ibid., p. 90.

7 A. A. Michelson, Light Waves and Their
Uses (Chicago: Univ. Chicago Press, 1903), p. 159.

8 Shankland, "The Michelson-Morley Experiment," p. 32.

9 Ibid.

10 R. S. Shankland, "Rayleigh and Michelson," Isis, 1967, 58: 87.

11 Loyd S. Swenson, Jr., "The Ethereal Aether: A History of the Michelson-Morley Aether-Drift Experiments, 1880-1930," dissertation, Claremont Graduate School, 1962. I am grateful to Dr. Swenson for letting me read his thesis and for several useful discussions. 
son and Morley were so discouraged by the null result of their experiment in 1887 that they disregarded their stated promise that their measurements, which they had taken during only six hours (spread over five days), "will therefore be repeated at intervals of 3 months, and thus all uncertainty will be avoided." Instead, Michelson stopped their work on this experiment and turned to the new use of the interferometer for measuring lengths (which, it turned out, led to his Nobel prize).

In short, to everyone's surprise, including Michelson's, the experiment had turned out to be one of "test" instead of merely "application," to use the terminology of Duhem. Indeed, it was threatening to become for ether theoreticians even malgrè lui, a crucial experiment in the only valid sense of the term, namely as the pivotal occasion causing a significant part of the scientific community to re-examine its previously held basic convictions.

We may gather that for Michelson the experiment was a source of discomfort and perhaps real unhappiness throughout his life, not only because of the null result, but also because of its various explanations. Initially he had felt his findings could only mean that the hypothesis of a stationary ether was incorrect; but the alternatives were no better. The idea that the ether is substantially carried along by the earth was in direct conflict with the well-established results of aberration experiments and Fizeau's measurement of the Fresnel dragging coefficient. And the modification of G. G. Stokes' theory of the ether, which Michelson came to favor, was shown to be untenable by better theoreticians, such as Lorentz, and by the negative result of Oliver Lodge's experiment on the supposed ether drag in the vicinity of rapidly moving discs. Lodge himself confessed impatience with the bothersome Michelson experiments which provided evidence against the existence of a nonviscous ether stagnant in space. Thus Lodge wrote, with only the slight exaggeration that others were to use later: "The one thing in the way of a simple doctrine of an ether undisturbed by motion is Michelson's experiment, viz., the absence of a second-order effect due to terrestrial movement through free ether. This experiment may have to be explained away."12

At Chicago in the spring of 1897 Michelson tested the possibility of a differential ether drag at different altitudes, and therefore the applicability of Stokes' hypothesis, which he continued to favor. But the large vertical interferometer also gave negative results. Michelson now was clearly rather exasperated: "One is inclined to return to the hypothesis of Fresnel and try to reconcile in some other way the negative results" of the earlier ether-drift experiments. ${ }^{13}$

Much later, when Michelson came to write the Studies in Optics, published in 1927 at the age of seventy-five, he had to end the chapter on "Effects of Motion of the Medium on Velocity of Light"-the subject on which he had spent much of his life-with a question he still could not answer: "It must be admitted,

12 Transactions of the Royal Society, July 1893, 184: 753. As we shall see, two years later Lorentz could cite two other long-known measurements that also were not in accord with the predictions of the ether theory.

13 Swenson, op. cit., p. 205, quoting Michelson, American Journal of Science, 1897, 3: 478. 
however, that these experiments are not sufficiently conclusive to justify the hypothesis of an ether which is entrained with the earth in its motion. But then, how can the negative results be explained?"14

By that time two other options had appeared. In his next chapter Michelson turned first to the proposal by Lorentz and G. F. FitzGerald to explain the "null effect by assuming a contraction in the material of the support for the interferometer just sufficient to compensate for the theoretical difference in path." But he immediately added, "such a hypothesis seems rather artificial."15 We note in passing a point that will loom large later-that even to this experimental physicist most sorely in need of an explanation, the Lorentz-FitzGerald hypothesis seemed "artificial," or, to use the terminology of others who expressed the same objection, too patently ad hoc. ${ }^{16}$

As to the other explanation-that implied in Einstein's relativity theoryMichelson, who had long held out against it, now in 1927 proposed a "generous acceptance" of the theory, notwithstanding many "paradoxical" consequences. But it was not a wholehearted acceptance, because "the existence of an ether appears to be inconsistent with the theory," and that seemed to him to be an overwhelming defect: "It is to be hoped that the theory may be reconciled with the existence of a medium, either by modifying the theory, or, more probably, by attributing the requisite properties to the ether." 17 At another occasion, also in 1927, Michelson in his last paper published before his death referred to the ether in the following nostalgic words: "Talking in terms of the beloved old ether (which is now abandoned, though I personally still cling a little to it). . ."18

If the result of the Michelson experiment was a mystery for a long time (Swenson has shown that it remained inconclusive into the $1920^{\prime} \mathrm{s}^{19}$ ), the relativity theory was to most physicists even more mysterious at its announcement in 1905 and for some time afterward. The lag of acceptance of the theory is a major research topic of its own. It took several years before one could say that even among German scientists there was a preponderance of opinion in favor of it, the turning point coming perhaps with the publication in 1909 of Hermann Minkowski"s address "Space and Time." ${ }^{20}$ In fact, the very first response within the scientific community to Einstein's relativity paper, in the same journal in which he had published it, was a categorical experimental disproof of the theory by W. Kaufmann. ${ }^{21}$ For years after Einstein's first publication no new experimental results came forth which could be used to "verify" his theory in the way most physicists were and still are used to look for verification, and it took until 1915 for Kaufmann's experimental equipment to be shown to have been defective. As

14 A. A. Michelson, Studies in Optics (Chicago: Univ. Chicago Press, 1927), p. 155.

15 Ibid., p. 156.

16 Moreover, as was realized by and by, the Lorentz-FitzGerald contraction was by no means sufficient to provide the needed relativistic basis for electromagnetic phenomena. We shall come back to this point in due course.

17 Ibid., p. 161.
18 "Conference on the Michelson-Morley Experiment," p. 342.

19 See "The Ethereal Aether."

$20 \mathrm{H}$. Minkowski, "Space and Time," reprinted in The Principle of Relativity (New York: Dover, n.d.), pp. 73-91.

21 G. Holton, "On the Origins of the Special Theory of Relativity," Am. J. Phys., 1960, 28: 634 . 
Max Planck noted in 1907, Michelson's was then still regarded as the only experimental support. ${ }^{22}$ The perceptive physicist W. Wien had published his earlier disagreement with relativity and was not convinced of the theory until 1909, and then it was not by any clear-cut evidence from experiment, but on aesthetic grounds, in words which Einstein must have appreciated: "What speaks for it most of all, however, is the inner consistency which makes it possible to lay a foundation having no self-contradictions, one that applies to the totality of physical appearances, although thereby the customary conceptions experience a transformation." 23

In retrospect it seems therefore inevitable that during the decade following Einstein's 1905 paper there occurred-especially in the didactic literature-a symbiotic joining of the puzzling Michelson experiment and the all-but-incredible relativity theory. The undoubted result of Michelson's experiments could be thought to provide an experimental basis for the understanding of relativity theory, which otherwise seemed contrary to common sense itself; the relativity theory in turn could provide an explanation for Michelson's experimental result in a manner not as "artificial" or "ad hoc" as reliance on the supposed LorentzFitzGerald contraction was widely felt to be. It has proved to be a long-lasting marriage.

\section{Implicit History in Didactic Accounts}

A look at the secondary material-the frame of reference in which everyone receives his first orientation-will show the degree to which the work of Einstein and Michelson is linked, and the additional pedagogical reasons for this tendency.

Long before we read professional literature of the kind in which Millikan's statement was published, most of us will have been told in our first physics courses what relation supposedly existed between Michelson's experiments and Einstein's work. To be sure, it is not the job of the usual physics textbooks to

22 M. Planck, "Zur Dynamik bewegter Systeme," Sitzungberichte der Akademie der Wissenschaften in Berlin, 1907, 29: 542.

$23 \mathrm{~W}$. Wien, Über Elektronen (2nd ed., Leipzig: Teubner, 1909), p. 32. I thank S. Goldberg for bringing this and the previous reference to my attention. Similar references are also given in the useful paper "The Lorentz Electron Theory and Relativity" (in press), by K. F. Schaffner, whom I thank for a preprint of his paper, received shortly before completing this study.

Max von Laue, in his text of 1911 on relativity theory, still had to confess that "a really experimental decision between the theory of Lorentz and the theory of relativity is indeed not to be gained; and that the former, in spite of this, has receded into the background, is chiefly due to the fact that, close as it comes to the theory of relativity, it still lacks the great simple universal principle, the possession of which lends the theory of relativity from the start an imposing appearance" (Das Relativitätsprinzip, Braunschweig: Vieweg, 1911, pp. 19-20). And we shall soon see how short the list was that Einstein himself gave for the results achieved by the relativity theory up to 1915 .

What made special relativity theory at last a widely accepted basic part of physics were developments far from the scope of Einstein's 1905 paper itself-foremost among them the experimental successes such as the eclipse expedition of 1919 with its successful test of a prediction of the general theory of relativity, the use of relativistic calculations to explain the fine structure of spectral lines, and the Compton effect. In the meantime the interested public and indeed many physicists had to look for support for relativity theory, particularly in the face of its challenging paradoxes and iconoclastic demands, in the ease with which it explained Michelson's results. 
teach history of science or even to imply it, but with the best intention in the world they do so. As a result there exists a widely shared, popular, "implicit" history of science. Indeed, since few students take bona fide history of science courses, implicit history is the version most widespread; because of its pervasiveness it is also the version that may well shape the judgment of future historians.

On the question under study here (as on so much else) the textbooks are virtually unanimous. Selected practically at random from recent books on my own shelf, the following is a typical quotation, to be found in the excellent text by Robert B. Leighton, Principles of Modern Physics. The book starts with the theory of relativity in Chapter I, explains the Michelson-Morley experiment in Section 1, and finds, "Einstein finally proposed a radically different approach to the problem posed by the Michelson-Morley experiment. He explained its null result simply by returning to the principle of relativity. . . ."24 Many statements with the same implication can readily be found in other textbooks, including some of my favorite ones. ${ }^{25}$

Although none of the authors actually commits himself unambiguously to a statement of cause and effect, the passages give generally the impression that there was a direct genetic link. Why is this so? The simplest hypothesis would be that it was true. But even before we check this possibility, we must note two suspicious circumstances. In the first place, the Michelson experiments do not necessarily entail Einstein's relativity theory. As H. P. Robertson put it in his

24 R. B. Leighton, Principles of Modern Physics (New York: McGraw-Hill, 1959), p. 5; italics supplied.

25 "[The Michelson-Morley experiment] was one of the most remarkable experiments in the nineteenth century. Simple in principle, the experiment led to a scientific revolution with far-reaching consequences." Charles Kittel, Walter D. Knight, and Melvin A. Ruderman, Mechanics (New York: McGraw-Hill, 1965), p. 332; italics supplied.

"As mentioned above, attempts were made to determine the absolute velocity of the earth through the hypothetical 'ether' that was supposed to pervade all space. The most famous of these experiments is one performed by Michelson and Morley in 1887. It was 18 years later before the negative results of the experiment were finally explained, by Einstein." Richard Feynman, Robert B. Leighton, and Matthew Sands, The Feynman Lectures on Physics, Vol. I (Reading, Mass.: AddisonWesley, 1963), p. 15-3.

"Michelson and Morley found that the speed of the earth through space made no difference in the speed of light relative to them. The inference is clear, either that the earth moves in some way through the ether space more slowly than it moves about the sun, or that all observers must find that their motion through space makes no difference in the speed of light relative to them. The above inference was clear, at least to Einstein, who knew of the 'unsuccessful attempts to discover any motion of the earth relative to the "light medium." " James A. Richards Jr., Frances W. Sears, M. Russell Wehr, and Mark W. Zemansky, Modern College Physics (Reading, Mass.: Addison-Wesley, 1962), p. 769; italics supplied.

"After a period of adjustment and speculation, with varying degrees of success, this famous experimental result [of Michelson and Morley] led to a more far-reaching postulate, one of the basic pillars of Einstein's Relativity Theory." G. Holton, Introduction to Concepts and Theories of Physical Science (Cambridge, Mass.: Addison-Wesley, 1952), p. 506; italics supplied.

Though they are very much in the minority, we must not fail to mention that a few textbook authors do not imply a genetic connection between the Michelson experiments and Einstein's relativity theory, and a few even specifically disclaim such a connection. Examples of this minority are R. B. Lindsay and H. Margenau, Foundations of Physics (New York: John Wiley, 1936), R. A. R. Tricker, The Assessment of Scientific Speculation (London: Mills \& Boon, 1965), A. P. French, Special Relativity (New York: Norton, 1968), and R. Resnick, Introduction to Special Relativity (New York: John Wiley, 1968). 
searching review article "Postulate versus Observation in the Special Theory of Relativity":

The kinematical background for this theory, an operational interpretation of the Lorentz transformation, was obtained deductively by Einstein from a general postulate concerning the relativity of motion and a more specific postulate concerning the velocity of light. At the time this work was done an inductive approach could not have led unambiguously to the theory proposed, for the principal relevant observations then available, notably the "ether-drift" experiment of Michelson and Morley (1886), could be accounted for in other, although less appealing, ways. ${ }^{26}$

The second point is that in the textbook passages no evidence is ever given to back up the implication of a genetic link; and in the absence of clear evidence either way, the likelihood is a priori great that a pedagogic presentation on any scientific subject will suggest a link from experiment to theory. Almost every science textbook of necessity places a high value on clear, unambiguous inductive reasoning. The norm of behavior in the classroom would seem to be threatened if the text were to allow that correct generalizations have sometimes been made without a base in unambiguous experimental evidence.

Moreover, in the textbooks or survey course, where a large amount of ground has to be covered, it is likely (for reasons of space or time if for no other) that one suitable experiment will be selected which can be convincingly presented, rather than a number of different experiments which may be equally good or better candidates. Of course, the dramatic qualities of the Michelson experiment enhance its position as candidate even more.

In the case of relativity theory, the author of a didactic account has an added incentive to foreshorten the period of doubt and uncertainty in the scientific community that followed Einstein's 1905 publication. A student can be expected to accept more easily a theory as non-commonsensical as Einstein's if he can be shown that Einstein, or at least Einstein's readers, became convinced on the basis of some clear-cut experiment.

For such reasons little is said in textbooks about the dramatic battles that are sometimes required for the gradual acceptance of a new theory. That lack incidentally fits in well with another moralizing function of textbooks-to underplay the scientist's personal involvement and struggle in the pursuit of his work and so to introduce the student to what the textbook author usually, perhaps unconsciously, conceives to be the accepted public norms of professional behavior. Texts do not want to deal with the "private" aspect of science, which can be so different from scientist to scientist and is so far from fully understood in any case. It is simpler to deal with the "public" side of science, on which there is (though perhaps falsely) some consensus. Therefore, the elements that will hold our attention in this essay, the elements that carry the possibility for a classic case study of the difference between private and public science-or for that matter of the relative roles of theory and experiment in modern scientific innovation and of the quasi-aesthetic criteria for decision between rival

26 Rev. Mod. Phys., 1949, 21: 378. 
conceptual systems embracing the same "facts"-give way in textbooks to other, simpler purposes.

The pedagogic usefulness of designating the Michelson experiments as the specific starting point for relativity has on a few occasions been honestly stated. Thus Henri Bergson, in Duration and Simultaneity, begins Chapter I, "HalfRelativity," in the following way:

The theory of relativity, even the "special" one, is not exactly founded on the Michelson-Morley experiment, since it expresses in a general way the necessity of preserving a constant form for the laws of electromagnetism when we pass from one system of reference to another. But the Michelson-Morley experiment has the great advantage of stating the problem in concrete terms and also spreading out the elements of its solution before our very eyes. It materializes the difficulty, so to speak. From it the philosopher must set forth; to it he will continually have to return, if he wishes to grasp the true meaning of time in the theory of relativity. ${ }^{27}$

It should also be mentioned on behalf of the textbook author that he rarely contradicts what the most prominent scientists themselves are expressing in their own popular and didactic writings. In this case the agreement among physicists has been as striking as among text writers, and its direction is that exhibited by Millikan's opinion. An earlier example-of a physicist who was also the author of the first serious textbook on relativity (1911) - is Max von Laue, who included this estimate:

The negative result of the Michelson experiment, however, forced it [the Lorentz theory of the stagnant ether] to make a new hypothesis which led over to the relativity theory [zur Relativitätstheorie hinüberleitenden Hypothese]. In this way, the experiment became, as it were, the fundamental experiment for the relativity theory, just as starting from it [the experiment] one reaches almost directly the derivation of the Lorentz transformation which contains the relativity principle. ${ }^{28}$

27 Henri Bergson, Duration and Simultaneity (originally published as Durée et Simultanéité, Paris: Alsin, 1922; reprinted in translation, New York: Bobbs-Merrill, 1965) p. 9; italics supplied. We note that here, as in the quotation of von Laue below, too much power is assigned to the conclusions that can be deduced from the experiment concerning the transformation equations. But these passages were of course written before the results of the Kennedy-Thorndike experiment (1932) and the Ives-Stilwell experiment (1938).

Another honest assessment of the usefulness of the approach Bergson outlined is given in Mary B. Hesse, Forces and Fields, The Concept of Action at a Distance in the History of Physics (London: Thomas Nelson, 1961 ), p. 226:

The experimental basis of the special theory of relativity is generally taken to be the Michelson-Morley experiment. This was not the only experiment which found its most convenient explanation in terms of that theory, for there were others concerning the optical and electromagnetic properties of moving bodies which led in the same direction, but since the MichelsonMorley experiment is familiar and comparatively simple, it will be convenient to use it in an analysis of the logical status of the theory.

See also E. Meyerson, La Deduction Relativiste (Paris: Payot, 1924), pp. 110-113, and E. Cassirer, "Einstein's Theory of Relativity," in Substance and Function, and Einstein's Theory of Relativity (New York: Dover, 1953 ), p. 375.

28 Von Laue, Das Relativitätsprinzip, p. 13. (Unless indicated to the contrary, all translations from German sources have been prepared by the author.)

Another distinguished example is provided by Arthur Holly Compton, a Nobelist and ex-colleague of Michelson: "This experiment [Michelson-Morley's] more than anything else was the occasion for the development of the 
It is very significant that Einstein himself, in his frankly didactic publications, has left some of his readers with a similar impression about the relation of his theory to Michelson's work. For example, in his early gemeinverständliche book Uber die spezielle und die allgemeine Relativitätstheorie a sequence is set forth which was to become so familiar in text presentations:

... for a long time the efforts of physicists were devoted to attempts to detect the existence of an ether-drift at the earth's surface. In one of the most notable of these attempts Michelson devised a method which appears as though it must be decisive. ... But the experiment gave a negative result-a fact very perplexing to physicists. Lorentz and FitzGerald rescued the theory from this difficulty by assuming that the motion of the body relative to the ether produces a contraction of the body in the direction of motion. . . . But on the basis of the theory of relativity the method of interpretation is incomparably more satisfactory. ${ }^{29}$

Without having actually said anything about his own historical route, Einstein's singling out of the Michelson experiment in this and other didactic writings during the first decade of relativity theory cannot have failed to influence and reinforce didactic writings by others-even after the subsequent publication of Einstein's very different and frankly historical accounts, to be discussed later.

One of the most interesting of Einstein's early articles, sometimes cited as an historical document on the influence of Michelson's experiment, is his contribution on "Relativity Theory" to a collection of thirty-six essays by foremost physicists, intended to convey the "state of physics in our time."30 Einstein begins: "It is hardly possible to form an independent judgment of the justification of the theory of relativity, if one does not have some acquaintance with the experiences

theory of relativity. ..." Quoted in Marjorie Johnston, ed., The Cosmos of Arthur Holly Compton (New York: A. A. Knopf, 1967), p. 196, from an essay published originally in 1931.

29 Albert Einstein, Über die spezielle und die allgemeine Relativitätstheorie (Braunschweig: Vieweg, 1917); republished in later editions and translations, e.g., New York: Crown Publishers, 1961, pp. 52-53.

An earlier discussion along these lines is contained in Einstein's “Über das Relativitätsprinzip und die aus demselben gezogenen Folgerungen," published in 1908 in the Jahrbuch der Radioaktivität und Elektronik, 4: 411-462. The article had originally been commissioned as a review essay by the journal's editor, J. Stark. It is explicitly not an historical review; Einstein says, "In what follows the attempt is made to pull together into a coherent whole [zu einem Ganzen] the publications which so far have come out of the unifications of H. A. Lorentz's theory and the principle of relativity. ... In this I follow the publications of $H$. A. Lorentz [1904] and A. Einstein [1905]." Here again we find a sequence of sentences which can be considered implicit history:

However, the negative results of the experiment of Michelson and Morley show that in a certain case also an effect of second order is absent, although it should have been noticeable on the basis of the Lorentz theory. It is known that this contradiction between theory and experiment was formally removed through the assumption by Lorentz and FitzGerald, according to which moving bodies experience a certain contraction in the direction of their motion. This assumption, introduced ad hoc, appeared however to be an artificial means to rescue the theory.

Einstein continues, still in a neutral and passive voice, to say that to overcome the difficulty it turned out "surprisingly" that all one had to do was to understand the concept of time sharply enough, that is, to recognize that the auxiliary quantity Ortszeit, introduced by Lorentz, should be defined as "time" itself. Only the idea of a light ether had to be given up.

${ }^{30}$ Die Physik, ed. E. Warburg (Leipzig: Teubner, 1915), pp. 703-713. 
and thought processes which preceded it. Hence, these must be discussed first." There follows a discussion of the Fizeau experiment, leading to Lorentz's theory based on the hypothesis of the stagnant ether. Despite its successes, "the theory had one aspect which could not help but make physicists suspicious"31: it seemed to contradict the relativity principle, valid in mechanics and "as far as our experience reaches, generally" beyond mechanics also. According to it, all inertial systems are equally justified. Not so in Lorentz's theory: a system at rest with respect to the ether has special properties; for example, with respect to this system alone, the light velocity is constant. "The successes of Lorentz's theory were so significant that the physicists would have abandoned the principle of relativity without qualms, had it not been for the availability of an important experimental result of which we now must speak, namely Michelson's experiment." There follows a description of the experiment and of the contraction hypothesis invoked by Lorentz and FitzGerald. Einstein adds to it sharply, "This manner of theoretically trying to do justice to experiments with negative result through ad hoc contrived hypotheses is highly unsatisfactory." ${ }^{32}$ It is preferable to hold on to the relativity principle, and to accept the impossibility-in-principle of discovering relative motion. But how is one to make the principle of constancy of light velocity and the principle of relativity after all compatible? "Whoever has deeply toiled with attempts to replace Lorentz's theory by another one that takes account of the experimental facts will agree that this way of beginning appears to be quite hopeless at the present state of our knowledge."33

Rather, Einstein continues, one can attain compatibility of the two apparently contradictory principles through a reformulation of the conception of space and time and by abandoning the ether. The rest of Einstein's short essay is concerned with the introduction of the relativity of simultaneity and of time, the transformation equations, and the length measurement of a rod moving with respect to the observer. "One sees that the above-mentioned hypothesis of $\mathrm{H}$. A. Lorentz and FitzGerald for the explanation of the Michelson experiment is obtained as a consequence of the relativity theory." ${ }^{34}$ But this result does not seem to be worthy of listing as one of the achievements of the relativity theory a little later: "We will now briefly enumerate the individual results achieved so far for which we have the relativity theory to thank." The list, as of 1915, was not long: "a simple theory of the Doppler effect, of aberration, of the Fizeau experiment"; applicability of Maxwell's equations to the electrodynamics of moving bodies, and in particular to the motion of electrons (cathode rays, $\beta$-rays) "without invoking special hypotheses"; and "the most important result," the relation between mass and energy, although for that there was then no direct experimental confirmation.

The sequence of ideas in this essay is illuminating. But it is plainly dangerous to quote only the introductory two sentences and the reference to the Michelson experiment and to call these an "historic account," as some have done in order to imply that Einstein followed this road himself. The whole essay is introduced

31 Ibid., p. 705.

32 Ibid., p. 707.
33 Ibid., pp. 707-708.

34 Ibid., p. 712. 
as dealing with the "justification" of the theory of relativity, not with the genesis. Einstein is saying that "the physicists" would have abandoned the principle of relativity had it not been for the Michelson experiment. Antony Ruhan at the University of Chicago, in an unpublished draft essay, perceptively comments on this passage: "the obvious meaning of this text is that Einstein regarded the experiment of Michelson and Morley as necessary to convince the majority of physicists of the validity of the theory of relativity. This is quite a different point from regarding it as a basis for one's personal discovery of the key to relativity." 35

To summarize the discussion so far, we have noted strong pressures in the same direction arising from two main sources: (1) the particular history surrounding the difficulties in acceptance of the Michelson results and the Einstein publication, and (2) the particular missions of pedagogic accounts backed up by the popular writings of distinguished physicists. These pressures have tended to the same end-to proclaim the existence of a genetic link between Michelson's and Einstein's work.

To be sure, we have so far not proven whether or not there was such an historical connection. To do that, we shall from Section V on seek the answer in more appropriate documents than didactic writings. But before we turn to such documents and to explicitly historical writings, we must at least briefly note another set of pressures that bore on the question before us: this was the weight of a philosophical view concerning science as a whole, supported by a vocal group of philosophers in the United States and Europe and widely current, par-

35 A. Ruhan, private communication, draft, p. 138. There are other discussions of this type to be found in Einstein's manuscripts and articles. An interesting glimpse of Einstein's classroom lectures on relativity, with special attention to his use of experiments, is furnished by Einstein's manuscript notebook which he used in preparation for his lectures in Berlin. Entitled "Relativitäts Vorlesungen, Winter 1914-15" (now kept at the Einstein Archive at the Institute for Advanced Study in Princeton), it was composed about the same time as his article in Die Physik and shows a similar structure. The Fizeau and aberration experiments are mentioned on the first page of the notebook and later are developed, with the characterization "Erfahrungs-Resultat." The Michelson experiment is mentioned next, with the notation: "erwies sich als nicht zutreffend. Verkürzung in Bewegungsrichtung eingeführt. Unbefriedigend, weil Hypothesen ad hoc."

On another pedagogic occasion, in a lecture "On the Theory of Relativity" at King's College, London, in 1921, Einstein said:

... I am anxious to draw attention to the fact that this theory is not speculative in origin; it owes its invention entirely to the desire to make physical theory fit obscured fact as well as possible. . . The law of the constant velocity of light in empty space, which has been confirmed by the development of electrodynamics and optics, and the equal legitimacy of all inertial systems (special principle of relativity), which was proved in a particularly incisive manner by Michelson's famous experiment, between them made it necessary, to begin with, that the concept of time should be made relative, each inertial system being given its own special time. (Ideas and Opinions, New York: Crown Publishers, 1954, p. 246.)

This talk was delivered toward the end of the period in which Einstein still used the language of the empiricist interpretation of science and just before the posthumous publication of Mach's attack on relativity theory, which formed a kind of turning point in Einstein's writings. I have discussed this change, including the position taken in his talk, in "Mach, Einstein, and the Search for Reality," Dædalus, 1968, 97: 649-650. 
ticularly after the victories of the empiricist schools around the turn of the century.

\section{The Experimenticist Philosophy of Science}

There exists a view of science at the extreme edge of the time-honored tradition of empiricism that will here be called experimenticism. It is best recognized by the unquestioned priority assigned to experiments and experimental data in the analysis of how scientists do their own work and how their work is incorporated into the public enterprise of science. A few examples will suffice to indicate the pervasiveness of this attitude. With specific reference to relativity theory, it is well illustrated by the views of Ernst Mach's disciple Joseph Petzoldt, the moving spirit behind the Gesellschaft für positivistische Philosophie of Berlin and its journal, Zeitschrift für positivistische Philosophie. In the lead article of the inaugural issue (1913), he printed the text of his speech delivered at the opening session of the Gesellschaft on 11 November 1912: With relativity theory had come "the victory over the metaphysics of absolutes in the conceptions of space and time," and a "fusion of mathematics and natural science which at last and finally shall lead beyond the old rationalistic, Platonic-Kantian prejudice."36 But the fixed hinge on which these desired events turned was, again, the Michelson experiment:

Clarity of thinking is inseparable from knowledge of a sufficient number of individual cases for each of the concepts used in investigation. Therefore, the chief requirement of positivistic philosophy: greatest respect for the facts. The newest phase of theoretical physics gives us an exemplary case. There, one does not hesitate, for the sake of a single experiment, to undertake a complete reconstruction. The Michelson experiment is the cause and chief support of this reconstruction, namely the electrodynamic theory of relativity. To do justice to this experiment, one has no scruples to submit the foundation of theoretical physics as it has hitherto existed, namely Newtonian mechanics, to a profound transformation. ${ }^{37}$

The full ambitions of the group and their perception of the real enemy were further shown in the next volume, where Petzoldt wrote, "Lorentz's theory is, at its conceptual center, pure metaphysics, nothing else than Schelling's or Hegel's Naturphilosophie." Again, the Michelson experiment, as the one and only experiment cited, is given the credit for ushering in a new era: “. . . the Einsteinian theory is entirely tied to the result of the Michelson experiment, and can be derived from it." Einstein himself "from the beginning conceived of the Michelson experiment relativistically. We are dealing here with a principle, a foremost postulate, a particular way of understanding the facts of physics, a view of nature, and finally a Weltanschauung. . . . The line Berkeley-Hume-Mach shows us our direction and puts into our hands the epistemological standard."38

A few years before, Michelson had been awarded the 1907 Nobel prize in

36 J. Petzoldt, "Positivistische Philosophie," Zeitschrift für positivistische Philosophie, 1913, 1: 3-4.
37 Ibid., p. 8; italics added. 11. 
physics, not for the experiments we have been discussing but "for his optical precision instruments and the search which he has carried out with their help in the fields of precision metrology and spectroscopy." The relativity theory was, of course, still far too new, and regarded as too speculative, to be mentioned in the citations or responses. (Indeed, by the time Petzoldt was writing his eulogies to it the theory had become too speculative for Mach himself, while the Nobel Prize Committee did not award Einstein's prize until 1922, and then, as Einstein was specifically reminded by the Committee, it was for contributions to mathematical physics and especially for his discovery of the [experimentally well-confirmed] law of the photoelectric effect ${ }^{39}$ ). In any case, theory was not now of interest at the 1907 award ceremony; the text of the presentation speech (by K. B. Hasselberg) showed the award to Michelson to be clearly motivated by the experimenticist philosophy of science:

As for physics, it has developed remarkably as a precision science, in such a way that we can justifiably claim that the majority of all the greatest discoveries in physics are very largely based on the high degree of accuracy which can now be obtained in measurements made during the study of physical phenomena. [Accuracy of measurement] is the very root, the essential condition, of our penetration deeper into the laws of physics-our only way to new discoveries. It is an advance of this kind which the Academy wishes to recognize with the Nobel Prize for Physics this year. (Italics supplied.)

Somehow, everyone managed to keep a decorous silence on the experiments which Petzoldt and others of his persuasion were to hail as the crucial turning point for physics and Weltanschauung; nobody referred here to Michelson's ether-drift experiments-neither the Swedish hosts nor Michelson himself in his responding lecture ("Recent Advances in Spectroscopy"). These experiments were as embarrassing for experimenticists with ether-theoretic presuppositions as they were welcome for experimenticists with relativistic presuppositions.

The even more extreme view that all scientific advance arises out of the use of instruments was defended by Millikan in his autobiography, where he explained that he moved from the University of Chicago to the California Institute of Technology because there "science and engineering were merged in sane proportions." He set forth his ideological basis as follows:

Historically, the thesis can be maintained that more fundamental advances have been made as a by-product of instrumental (i.e. engineering) improvement than in the direct and conscious search for new laws. Witness: (1) relativity and the Michelson-Morley experiment, the Michelson interferometer came first, not the reverse; (2) the spectroscope, a new instrument which created spectroscopy; (3) the three-electrode vacuum tube, the invention of which created a dozen new sciences; (4) the cyclotron, a gadget which with Lauritsen's linear accelerator spawned nuclear physics; (5) the Wilson cloud chamber, the parent of most of

39 The official document, dated 10 Dec. 1922, of the Royal Swedish Academy of Sciences, now kept at the Einstein Archive, stated specifically that the Academy, "independent of the value that may be credited to the relativity and gravitation theory after eventual confirmation, bestows the prize ... to Albert Einstein, being most highly deserving in the field of theoretical physics, particularly his discovery of the law pertaining to the photoelectric effect." 
our knowledge of cosmic rays; (6) the Rowland work with gratings, which suggested the Bohr atom; (7) the magnetron, the progenitor of radar; (8) the counter-tube, the most fertile of all gadgets; (9) the spectroheliograph, the creator of astrophysics; (10) the relations of Carnot's reversible engine to the whole of thermodynamics. ${ }^{40}$

In the work of philosophers of science the discussion of relativity theory is frequently found linked tightly to the Michelson experiment, though rarely more enthusiastically than in Gaston Bachelard's essay "The Philosophical Dialectic of the Concepts of Relativity," in P. A. Schilpp's volume Albert Einstein: Philosopher-Scientist:

As we know, as has been repeated a thousand times, relativity was born of an epistemological shock; it was born of the "failure" of the Michelson experiment. ... To paraphrase Kant, we might say that the Michelson experiment roused classical mechanics from its dogmatic slumber. . . . Is so little required to "shake" the universe of spatiality? Can a single experiment of the twentieth [sic] century annihilate-a Sartrian would say "néantiser"-two or three centuries of rational thought? Yes, a single decimal sufficed, as our poet Henri de Regnier would say, to "make all nature sing." 11

And so on and so forth. Einstein chose not to respond to this apotheosis of the Michelson experiment in his replies at the end of the same volume. But he did make a lengthy and subtly devastating reply to another essay in this collection, that by Hans Reichenbach, which has a good deal of the same kind of experimenticist bias.

Reichenbach, who knew Einstein and corresponded with him at certain periods, was, over the years, one of the more persistent and interesting philosophical analysts of the epistemological implications of relativity. (He published, for example, several attempts to cast the theory into axiomatic form. To one of these attempts Einstein himself responded to say he did not find it convincing even on its own grounds; he wrote to Reichenbach on 19 October 1929, "In my view, the logical presentation which you give my theory is, to be sure, possible, but it is not the simplest one.") But Reichenbach's experimenticist conviction never flagged. For example, he wrote that Einstein's work "was suggested by closest adherence to experimental facts. ... Einstein built his theory on an extraordinary confidence in the exactitude of the art of experimentation." ${ }^{2}$ Again, the only historic experiment Reichenbach associated with the genesis of Einstein's theory was, of course, the Michelson experiment; for example, "the theory of relativity makes an assertion about the behavior of rigid rods similar to that about the behavior of clocks. . . . This assertion of the theory of relativity is based mainly on the Michelson experiment. . .."43

40 The Autobiography of Robert A. Millikan (New York: Prentice-Hall, 1950), p. 219.

41 In P. A. Schilpp, ed., Albert Einstein: Philosopher-Scientist (Evanston, Ill.: Library of Living Philosophers, 1949), pp. 566-568.

$42 \mathrm{H}$. Reichenbach, From Copernicus to Einstein (New York: Philosophical Library, 1942), p. 51.
$43 \mathrm{H}$. Reichenbach, The Philosophy of Space and Time (New York: Dover, 1957; a translation of Die Philosophie der RaumZeit Lehre, Berlin: Walter de Gruyter, 1928), p. 195. In a footnote, Reichenbach adds that the assertion "does not follow from this experiment alone," but no others are indicated. Reichenbach and his followers are forced to 
In his essay in Schilpp's collection, Reichenbach reverts to the same points ${ }^{44}$; but they are, as it were, only preludes to the conclusion that "it is the philosophy of empiricism, therefore, into which Einstein's relativity belongs. . . In spite of the enormous mathematical apparatus, Einstein's theory of space and time is the triumph of such a radical empiricism in a field which had always been regarded as a reservation for the discoveries of pure reason." ${ }^{55}$ In his reply to this essay Einstein devoted most of his attention to a denial of this claim. He preferred to hold fast to the basic conceptual distinction between "sense impressions" and "mere ideas"-despite the expected reproach "that, in doing so, we are guilty of the metaphysical "original sin." 46 Einstein pleads that one must also accept features not only of empiricism but also of rationalism, indeed that a "wavering between these extremes appears to be unavoidable." ${ }^{47}$ Einstein adopts the role of the "non-positivist" in an imaginary dialogue with Reichenbach and urges the useful lesson of Kant that there are concepts "which play a dominating role in our thinking, and which, nevertheless, cannot be deduced by means of a logical process from the empirically given (-a fact which several empiricists recognize, it is true, but seem always again to forget)." 48

give high prominence to the Michelson experiment in the supposed development of relativity theory, partly because of the claim that the experiment logically is not dependent on the theory:

The opinion has been expressed that the contraction of one arm of the apparatus is an "ad hoc hypothesis," while Einstein's hypothesis [that both arms are equally long in every inertial system] is a natural explanation as a consequence of the relativity of simultaneity. Both of these explanations are wrong. The relativity of simultaneity has nothing to do with the contraction in Michelson's experiment, and Einstein's theory explains the experiment as little as does that of Lorentz (pp. 195-196).

$$
\text { *** * * }
$$

It would be mistaken to argue that Einstein's theory gives an explanation of Michelson's experiment, since it does not do so. Michelson's experiment is simply taken over as an axiom (p. 201).

The same point is echoed by A. Grünbaum, who writes, "far from explaining the outcome of the Michelson-Morley experiment as a consequence of more fundamental principles, Einstein incorporated its null result as a physical axiom in his light principle." "Logical and Philosophical Foundations of the Special Theory of Relativity," in A. Danto and S. Morgenbesser, Philosophy of Science (New York: Meridian Books, 1960), p. 419. ${ }^{44} \mathrm{H}$. Reichenbach, "The Philosophical Significance of the Theory of Relativity," in Schilpp, Albert Einstein, e.g., p. 301.
45 Ibid., pp. 309-310.

46 A. Einstein, "Remarks concerning the Essays brought together in this Cooperative Volume [Reply to Criticisms]," in Schilpp, Albert Einstein, p. 673.

47 Ibid., p. 680.

48 Ibid., p. 678. A few pages later, Einstein summarizes his eclectic approach in a memorable passage (pp. 683-684):

The reciprocal relationship of epistemology and science is of noteworthy kind. They are dependent upon each other. Epistemology without contact with science becomes an empty scheme. Science without epistemology is-insofar as it is thinkable at all-primitive and muddled. However, no sooner has the epistemologist, who is seeking a clear system, fought his way through to such a system, than he is inclined to interpret the thought-content of science in the sense of his system and to reject whatever does not fit into his system. The scientist, however, cannot afford to carry his striving for epistemological systematic that far. He accepts gratefully the epistemological conceptual analysis; but the external conditions, which are set for him by the facts of experience, do not permit him to let himself be too much restricted in the construction of his conceptual world by the adherence to an epistemological system. He therefore must appear to the systematic epistemologist as a type of unscrupulous opportunist: he appears as realist insofar as he seeks to describe a world independent of the acts of 
The difficulty is, of course, one of relative scientific taste or style. To Reichenbach and his followers the interest in a scientific theory resides not in the details of its historical development, not in the work of an actual person. (As Reichenbach said honestly, "The philosopher of science is not much interested in the thought processes which lead to scientific discoveries; he looks for a logical analysis of the completed theory, including the relationships establishing its validity. That is, he is not interested in the context of discovery, but in the context of justification." ${ }^{2}$ ) But it is equally understandable that to the originator of the theory the "completed theory" in its public, developed, institutional or textbook form does not have the same exclusive interest.

Unfortunately, neither Reichenbach himself nor his followers always remembered his laudable attempt to distinguish sharply between private and public science, nor have they always adhered to his wise disclaimer of interest in the thought processes leading to the discovery. The desire to see a theory as a logical structure, built upon an empirical basis and capable of verification or falsification by more experiment, brings them to discuss presumed historical sequences on the road that led to the discovery; thus, implicit "history" is produced after all (for example, the confident assertion that "Einstein incorporated its [the Michelson experiment's] null result as a physical axiom in his light principle,"50 and similar attempts at "the unraveling of the history" of relativity theory). When direct evidence, which we shall examine below, against the priority of the Michelson experiment in Einstein's thinking is presented to the experimenticist, the response is this: Without the genetic role of this particular experiment, an understanding of the discovery of the theory would become "quite problematic," and one would be left "puzzled concerning the logical, as distinct from psychological grounds which would then originally have motivated Einstein to have confidence in the principle of relativity without the partial support of the Michelson-Morley experiment. ..." 51

As a curious postscript to this section, one might mention that the experimenticist interpretation of relativity has also been advocated under quite different circumstances, but none more macabre than the attempt in the 1920 's by some German scientists such as W. Wien to point to the supposed experimental origins of relativity in order to remove the theory from the arena of unthinking, inflamed opposition in some quarters in Germany against Einstein personally and against his work. ${ }^{52}$ In a small book published in 1921 Wien wrote that he wished

perception; as idealist insofar as he looks upon the concepts and theories as the free inventions of the human spirit (not logically derivable from what is empirically given); as positivist insofar as he considers his concepts and theories justified only to the extent to which they furnish a logical representation of relations among sensory experiences. He may even appear as Platonist or Pythagorean insofar as he considers the viewpoint of logical simplicity as an indispensable and effective tool of his research.

49 Reichenbach, "The Philosophical Significance of the Theory of Relativity," p. 292.

50 Grünbaum, "Logical and Philosophical Foundations of the Special Theory of Relativity," p. 419.

51 A. Grünbaum, Philosophical Problems of Space and Time (New York: Knopf, 1963), pp. 380-381.

52 For details of this turbulent period (1921-1922), see P. Frank, Einstein: Sein 
... to give an objective presentation of the theory of the pro and the contra concerning which much is being discussed in a rather unscientific way in public. I hope to have discussed the questions sine ira et studio, and I would like to advise everyone who concerns himself with the theory not to give himself out as a follower or an opponent of this theory, but rather to consider the theory in such a manner as is congruous with science, namely as one way to discover peculiarities of nature's laws which may equally well turn out to be right or wrong. The decision concerning this cannot be reached in a dogmatic way, but one must leave it up to the decision of experience. ${ }^{53}$

Wien then reassures his readers that the "relativity theory is, like all physical theories, a result of experience." It is not difficult now to guess the particular experience involved: "The negative result of the Michelson experiment is the fact of experience on which the relativity theory rests. This experiment is for this theory of equal significance as the perpetuum mobile is for the law of the conservation of energy. . . ."54 This attempt to experimentalize the basis of relativity, incidentally, did not gain acceptance sufficiently to save relativity theory during the Nazi period from the stigma of what was called then (and even as recently as 1954) "the formal rationalism of Jewish thinking."

\section{Explicit History}

After the nearly complete consensus and confidence implied in textbooks and in experimenticist works with epistemological intentions, we are prepared to find more variety and circumspection in the work of scholars who have undertaken to write explicitly historical accounts. This is indeed the case; there is far less agreement here. The existence of a whole spectrum of differently documented historical studies is itself an interesting problem.

To examine this spectrum and to arrange the items roughly in increasing order of intended seriousness as historical studies, we may start with The World of the Atom, published in 1966. In short sections based largely on secondary material and inserted between excerpts from original papers, the editors intend to provide some historical guidelines. On the issue of interest to us we find a familiar comment, but now curiously hedged: "The legacy of the Michelson-Morley experiment to atomic theory was tremendous, if indirect. It was the negative result of the experiment that in part led Einstein into one of the fundamental ideas upon which the theory of relativity rests, namely, that the speed of light is the same for all observers, regardless how they may be moving." ${ }^{56}$

Leben und seine Zeit (Munich: Paul List, 1949), esp. Chs. 7 and 8. (The Germanlanguage version of the book is preferable to the much less detailed English version.) Right-wing protest manifestos against relativity were being published even as Nazi terrorist activities were leading up to the attempted Putsch of 1923. Einstein's friend Rathenau was among those assassinated; Einstein was told he was in danger, too, and in fact he left Germany at that time.
$53 \mathrm{~W}$. Wien, Die Relativitätstheorie vom Standpunkt der Physik und Erkenntnislehre (Berlin: J. A. Barth, 1921), p. 3.

54 Ibid., p. 7.

55 Heinrich Lange, Geschichte der Grundlagen der Physics, Vol. I (Freiburg/Munich: Karl Alber, 1954), p. 301.

56 Henry A. Boorse and Lloyd Motz, eds., The World of the Atom (New York: Basic Books, 1966), p. 373. 
Another account that leaves open the extent or directness of the influence is given in a useful biography, Michelson and the Speed of Light, written primarily for high school students by the successful textbook and popular-science author Bernard Jaffe. Speaking of the original work on relativity, Jaffe writes that Einstein "saw the Michelson-Morley ether drift result as perfectly correct, since no ether drift should be expected under the conditions of the experiment." 57 "In this great upheaval in physics, the classic ether drift experiment of Michelson had been of fundamental significance. To contend, as some have done, that Einstein's Special Theory of Relativity was essentially a generalization of the Michelson experiment, and that it could not have been arrived at without the experiment, is to overstate the case." 58

Jaffe's biography incidentally does sound, if only faintly, a new note that has some significance for the understanding of the case. He writes, "Unwittingly, Michelson, as it turned out, had supplied the raw material for one of the great structures of science-a synthesis which was to be completed overseas. This was one of the very few instances when a basic discovery was made in America for European exploitation. Almost always it was the other way around."59 The pride in the American scientist was undoubtedly increased, once relativity theory became palatable, by seeing his work as the root of relativity. ${ }^{60}$

A more detailed analysis, with new documentation, has been provided over the last several years in a series of insightful articles by R. S. Shankland, Professor of Physics at Case Western Reserve University (formerly Case Institute of Technology, where the Michelson-Morley experiment was repeated before Michelson's departure first for Clark University and then, in 1894, for the University of Chicago). A particular merit of Shankland's work has been his publication of a number of letters from and to Michelson and his report on a series of interviews with Einstein during the period 1950-1954.

On the important question before us, Shankland's writings show a significant development. His earliest article is a short piece on Michelson for the collection Les Inventeurs célèbres-sciences physiques et applications. ${ }^{61}$ Subtitled "Expérience de base de la relativité," the article presents the experiment and the theory as closely coupled as in most of the above versions. ${ }^{62}$ Starting with Shankland's

57 Jaffe, Michelson and the Speed of Light, p. 99 .

58 Ibid., p. 100. Jaffe also reprints an interesting letter from Einstein which we shall take up at a later point together with Einstein's other direct responses to the same question.

59 Ibid., p. 90.

60 Michelson was America's first Nobel prize scientist (and, in 1907, the only American Nobelist other than Theodore Roosevelt, who had received the 1906 peace prize); the next American physicist so honored was Millikan (1923). There is some evidence that the Nobel award to Michelson had for American science some of the same significance in terms of increased national self-esteem as did
Yukawa's Nobel prize in physics (1949) for Japanese science.

61 R. S. Shankland, "Michelson 1852-1931, Expérience de base de la relativité," in Les Inventeurs célèbres-sciences physiques et applications (Paris: Lucien Mazenod, 1950), pp. 254-255.

62 Ibid., p. 255:

Contre toute attente, l'observation finale, faite en juillet 1887, ne permit de consstater aucun déplacement sensible dans les franges d'interférence. Ce résultat surprenant ne fut pas entièrement apprécié à l'époque, mais après le travail de pionnier de Fitz-Gerald et $\mathrm{H}$. A. Lorentz, Einstein le généralisa dans sa grande théorie de la Relativité restreinte de 1905, et l'expéri- 
next essay on this topic about a dozen years later, "Conversations with Albert Einstein," another aspect of the case begins to show up. His report (1963) is based on five visits with Einstein at Princeton; their conversations dealt principally with the work of Michelson, particularly the Michelson-Morley and Miller experiments, and with the subsequent studies that led to the clarification of Miller's results (in which Shankland himself took a leading part). This article is a valuable and rich resource which merits mining for all it is worth.

Near the beginning of Shankland's firsthand report we find the main reason for his visit-and a response of Einstein for which nothing we have read above has prepared us:

The first visit [4 February 1950] to Princeton to meet Professor Einstein was made primarily to learn from him what he really felt about the Michelson-Morley experiment, and to what degree it had influenced him in his development of the Special Theory of Relativity. ... He began by asking me to remind him of the purpose of my visit and smiled with genuine interest when I told him that I wished to discuss the Michelson-Morley experiment performed at Cleveland in 1887. . . . When I asked him how he had learned of the Michelson-Morley experiment, he told me that he had become aware of it through the writings of $\mathrm{H}$. A. Lorentz (Arch. Neerl. 2, 168 [1887], and many later references), but only after 1905 had it come to his attention! "Otherwise," he said, "I would have mentioned it in my paper." He continued to say the experimental results which had influenced him most were the observations on stellar aberration and Fizeau's measurements on the speed of light in moving water. "They were enough," he said. ${ }^{63}$

Shankland may well have been astonished by Einstein's disclaimer of the direct genetic role of the Michelson-Morley experiment in the creation of the theory of relativity. As if to make sure that he had understood properly, Shankland wisely raised the whole matter again at another visit, two and a half years later, on 24 October 1952.

I asked Professor Einstein where he had first heard of Michelson and his experiment. He replied, "This is not so easy, I am not sure when I first heard of the Michelson experiment. I was not conscious that it had influenced me directly during the seven years that relativity had been my life. I guess I just took it for granted that it was true." However, Einstein said that in the years 1905-1909, he thought a great deal about Michelson's result, in his discussions with Lorentz and others in his thinking about general relativity. He then realized (so he told me) that he had also been conscious of Michelson's result before 1905 partly through his reading of the papers of Lorentz and more because he had simply assumed this result of Michelson to be true. ${ }^{64}$

These two statements must be faced; their authenticity cannot be minimized. Here and elsewhere in these interviews one is impressed with Einstein's consistent responses and analyses, as well as with the evident readiness and joy with which he thought of the experiment and of Michelson as a person. (Thus Shank-

ence Michelson-Morley acquit sa juste place, en tant que l'une des expériences cruciales de l'histoire des sciences. Ses répétitions ultérieures ne firent que confirmer ce résultat et son importance pour la théorie de la Relativité.

63 Shankland, "Conversations," pp. 47-48; italics in the original.

64 Ibid., p. 55. 
land reports he said to him several times, "I really loved Michelson.") To be sure, as Shankland himself emphasizes, many of the events discussed between them had occurred some fifty years before their meetings; Einstein's age was seventy-one and seventy-three years at the time of these two interviews, and during another interview there are two minor episodes where his memory did not serve him absolutely faithfully (Shankland reports that Einstein had forgotten about a speech he gave in Berlin on Michelson's death in 1931, and also about Joos' work). But it would be far too simple to dismiss or play down the repeated, direct response to Shankland on a topic on which Einstein throughout his life had frequent occasion to ponder, write, and lecture, and on which he no doubt had often been asked questions.

The fact that the response is so contrary to practically all other accounts makes it imperative to reexamine the whole question in order to accommodate Einstein's statements: (1) that the Michelson experiment occupied his attention only after 1905 (although he was conscious of the result earlier); (2) that other, earlier ether experiments on stellar aberration and on the Fresnel ether-drag coefficient form the most important experimental bases for his 1905 paper; and (3) that insofar as he was aware of the Michelson result, he was evidently not specially impressed with it upon reading it in Lorentz's paper because he already had assumed it to be true on other grounds.

We shall see to what extent Einstein's response is consistent with a careful reading of his 1905 paper itself and with all other pertinent reports and documents by Einstein which I have been able to find. But it is clear already that when compared to the various confident pronouncements above, Einstein's responses in these interviews seem vague, indefinite, and tentative. It is as if we had been preparing a case for a specific "Yes" or "No," and, at last, encountering the person most involved, we received the unexpected answer, "Neither! That's not the way it happened, and in any case this was for me not really an important consideration." Einstein raises the distinct suspicion that the question may be as trivial or irrelevant to him as it is important to us or to Shankland, who started the series of visits "primarily to learn from him what he really felt about the Michelson-Morley experiment. . . ." It is doubly ironic to find at this point that neither Michelson nor Einstein regarded the famous experiment as decisive for himself, not to say "crucial."

In two later articles Shankland adopted the position that the problem that the Michelson-Morley experiment posed "led indirectly to Einstein's Special Theory of Relativity,"65 and "both postulates [of the 1905 paper] could, of course, be considered as having a close relationship to the Michelson-Morley experiment, but actually Einstein arrived at his theory by a less direct route, becoming aware of the observational material principally through the writings of Lorentz which he began to study as a student in 1895."66 But perhaps the most significant part of these two articles is the publication in both of a letter which Einstein had sup-

65 R. S. Shankland, "The Michelson-Morley Experiment," Scientific American, 1964, 211, No. 5: 107 .
${ }^{66}$ Shankland, "The Michelson-Morley Experiment," Am. J. Phys., 1964, 32: 34. 
plied, evidently on Shankland's invitation, for a special meeting of the Cleveland Physics Society on 19 December 1952, honoring the centenary of Michelson's birth. This letter, the result of a more careful and reflective response than may have been his viva voce answers to the question, is therefore of even greater value. More strongly than in the somewhat sketchy remarks in the interviews Einstein proposes a point of view for gaining a clearer understanding of his 1905 work on relativity. Following is the document published by Shankland, in which I have inserted alternative readings of some phrases or words in brackets, to indicate translations that would be somewhat more faithful to the copy of the original German text ${ }^{67}$ :

I always think of Michelson as the Artist in Science. His greatest joy seemed to come from the beauty of the experiment itself, and the elegance of the method employed. But he has also shown an extraordinary understanding for the baffling fundamental questions of physics. This is evident from the keen interest he has shown from the beginning for the problem of the dependence of light from [on] motion.

The influence of the crucial [famous] Michelson-Morley experiment upon my own efforts [deliberations] has been rather indirect. I learned of it through $\mathbf{H}$. A. Lorentz's decisive investigation of the electrodynamics of moving bodies (1895) with which I was acquainted before developing [setting forth] the Special Theory of Relativity. Lorentz's basic assumption of an ether at rest seemed to me not convincing in itself and also [replace and also by precisely] for the reason that it was leading to an interpretation of the result of [omit the result of] the MichelsonMorley experiment which seemed to me artificial. What led me more or less [omit more or less] directly to the Special Theory of Relativity was the conviction that the electro-motoric [electromotive] force acting on [induced in] a body in motion in a magnetic field was nothing else but an electric field. But I was also guided by the result of the Fizeau experiment and the phenomenon of aberration.

There is, of course, no logical way leading to the establishment of a theory but only groping constructive attempts controlled by careful consideration of factual knowledge. .8

67 Shankland published the English translation that was sent to him by Einstein, and he reports that he also received the German original; in both the author's holograph draft and the carbon copy of the latter (both these versions are now in the Einstein Archive at Princeton) the first two sentences are in English and appear to represent the acceptance by Einstein of a draft submitted for the occasion by Shankland on the basis of the interviews. Because of the significant differences between the German and English versions after the first two sentences, it would be of interest to find who made the English translation of Einstein's German original. For many years Einstein's friends and assistants helped him with English translations, but in this instance, according to Miss Helen Dukas, we may believe it was Einstein's own. She informed me that in his last years he sometimes made the translations himself.
68 Einstein's original text appears as follows in copies in the Einstein Archive:

I always think of Michelson as the Artist in Science. His greatest joy seemed to come from the beauty of the experiment itself, and the elegance of the method employed.

Aber er hat auch ein aussergewöhnliches Verständnis gezeigt für die fundamentalen Rätsel in der Physik. Dies sieht man aus dem Interesse, das er von Anfang an dem Problem der Abhängigkeit des Lichtes von der Bewegung entgegenbrachte.

Mein eigenes Nachdenken wurde mehs indirekt durch das berühmte MichelsonMorley Experiment beeinflusst. Ich erfuhr von diesem durch Lorentz' bahnbrechende Untersuchung über die Elektrodynamik bewegter Körper (1895), von der ich vor Aufstellung der speziellen Relativität Kenntnis hatte. Lorentz' Grundannahme vom ruhenden Aether schien mir gerade deshalb 
We first note some differences between the texts at important points. Thus the Michelson-Morley experiment is called "crucial" in the English translation (as it often is in the didactic literature) but "famous" (berïhmt) in the German original. But the most significant aspect of the document is the definite order of importance which Einstein assigned to four identified experiments. The one "experiment" cited here as having lead Einstein "directly" (in the German) or "more or less directly" (in the English text) to the special relativity theory is precisely the thought experiment that appears on the first page of his 1905 paper, namely, the motion of a conductor with respect to a magnetic field. The three other experiments were of some additional importance: the Fizeau and aberration experiments, whose results "also guided" Einstein, and the Michelson-Morley experiment, in its form presented by Lorentz in 1895. But even in this message on the centennial of Michelson's birth, Einstein assigns Michelson's experiment only the fourth rank as a historic stimulus: he reports that it had only a "rather indirect" role in his own work of 1905; specifically, the experiment (or rather its result) underlined the "artificial" character of the contraction hypothesis that seemed to be needed in order to rescue the conception of a stagnant ether-an artificial character, as we shall see, that was regretted by other physicists, including Lorentz himself.

This document, therefore, provides a likely scenario for the part played by experiments in the genesis of Einstein's 1905 paper. It is believable in itself, considering the authority of the statement. And we shall find that it also fits with all other direct and indirect evidence coming from Einstein, including his letters, his spoken answers to questions, and his original paper.

The final paragraph of the statement is rather startling. Here Einstein, having done his duty by writing this response to a specific question, goes beyond it and volunteers a glimpse of the methodological position that had also surfaced in his interviews with Shankland: "There is, of course, no logical way leading to the establishment of a theory but only groping constructive attempts controlled by careful consideration of factual knowledge." Entirely in accord with the honest self-appraisal of an original scientist, Einstein's forthright confession is yet so contrary to the widely current myths which present scientific work as the inexorable pursuit of logically sound conclusions from experimentally indubitable premises. Systematizers, axiomatizers, text writers, and others may yearn for linearized sequences both in scientific work itself and in accounts of it; the truth, alas, is different. Einstein had often mentioned this, for example in speaking to Shankland about the origins of his work of 1905. Shankland reports in "Conversations": "This led him to comment at some length on the nature of mental

nicht überzeugend, weil sie zu einer Interpretation des Michelson-Morley Experimentes führte, die mir unnatürlich erschien. Mein direkter Weg zur speziellen Relativitäts-Theorie wurde hauptsächlich durch die Ueberzeugung bestimmt, dass die in einem im Magnetfelde bewegten Leiter induzierte elektromotorische Kraft nichts anderes sei als ein elektrisches Feld. Aber auch das Ergebnis des Fizeau'schen Versuches und das Phänomen der Aberration führten mich.

Es führt ja kein logischer Weg zur Aufstellung einer Theorie, sondern nur tastendes Konstruieren mit sorgfältiger Berücksichtigung des Thatsachen-Wissens. 
processes in that they do not seem at all to move step by step to a solution, and he emphasized how devious a route our minds take through a problem. 'It is only at the last that order seems at all possible in a problem." "69 Similarly, in commenting on the correct view a historian should take of the work of physicists, Einstein told him: "The struggle with their problems, their trying everything to find a solution which came at last often by very indirect means, is the correct picture." 70

This view Einstein had expressed repeatedly-though not previously in this context-explicitly from about 1918 on and more emphatically from the early 1930's on. Examples may be found in his essay in honor of Max Planck in 1918 ("there is no logical way to the discovery of these elementary laws. There is only the way of intuition" based on Einfühlung in experience); in his Herbert Spencer lecture of 1933 (concerning the "purely fictitious character of the fundamentals of scientific theory"); in his "Autobiographical Notes" written in 1946 ("A theory can be tested by experience, but there is no way from experience to the setting up of a theory"71); in his reply to J. Hadamard, who had asked Einstein for a self-analysis of his thought processes ("The words or the language, as they are written or spoken, do not seem to play any role in my mechanism of thought. The psychical entities which seem to serve as elements in thought are certain signs and more or less clear images which can be 'voluntarily' reproduced and combined"72); and on many other occasions. ${ }^{73}$

In believing that there can be an essential abyss between experience and logically structured theory, and in believing also in the related "distinction between 'sense impressions' on the one hand and mere ideas on the other," which, as we noted, he confessed made him "guilty of the metaphysical 'original sin," "74 Einstein separated himself from his earlier positivistic allegiances and from most of the prominent philosophies of science of his time. That he did not do this lightly is indicated by the frequency with which he kept reiterating these points over the years. In this connection Einstein's document for the Michelson centenary will be a key to the final evaluation of the problem under discussion.

To round out this section on explicitly historical accounts, we turn to the relatively few other sources that have serious historical intentions. Here we find a great variety of opinions among authors. At one end E. Whittaker refers to "the Michelson-Morley experiment and the other evidence which had given rise to relativity theory" in his famous and amply discussed chapter entitled significantly "The Relativity Theory of Poincaré and Lorentz," in A History of Theories of Aether and Electricity. ${ }^{75}$ At the other end is T. W. Chalmers' Historic Researches:

69 Shankland, “Conversations," p. 48.

70 Ibid., p. 50.

71 A. Einstein, "Autobiographical Notes," in Schilpp, Albert Einstein, p. 89.

72 Jacques Hadamard, An Essay on the Psychology of Invention in the Mathematical Field (New York: Dover, 1954; originally, Princeton: Princeton Univ. Press, 1945), pp. 142-143.
73 See Holton, "Mach, Einstein, and the Search for Reality," pp. 636-637.

74 Einstein, "Reply to Criticisms," in Schilpp, Albert Einstein, p. 637.

$75 \mathrm{E}$. Whittaker, A History of Theories of Aether and Electricity, Vol. II: The Modern Theories, 1900-1926 (London: Thomas Nelson, 1953), p. 38. 
“... It should be made clear that, in spite of frequent statements to the contrary, the theory for relativity did not owe its inspiration and origin to the null result of the ether drift experiments. . . . had the ether drift experiments never been performed, the theory for relativity would have arisen in the way it did, but it would have lacked one of its several sources of experimental confirmation."76

The most comprehensive historical study of the Michelson experiment has recently been carried out by Loyd Swenson in his Ph.D. dissertation mentioned earlier-"The Ethereal Aether: A History of the Michelson-Morley Aether-Drift Experiments, 1880-1930." Swenson is not primarily concerned with the special question of this essay, but rather analyzes historically the idea of the experimentum crucis and specifically the way in which Michelson's experiments were discussed before and after 1905. A number of points useful for our examination have already been noted in Section II. In particular, Swenson gives additional evidence of the consternation which Einstein's relativity paper caused in the early days. Thus he cites William F. Magie's address of 28 December 1911 to the American Physical Society, of which he had just been elected president; Magie stated that relativity "may fairly be said to be based on the necessity of explaining the negative result of the famous Michelson-Morley experiment, and on the convenience of being able to apply Maxwell's equations of the electromagnetic field without change of form to a system referred to moving axes."77 Swenson continues, "Magie insisted on the counter-evidence that the principle of relativity was not essential to obtain explanations for the experiments by Fizeau, Mascart, Brace, nor those of Kaufmann and Bucherer. Why then, he [Magie] asked, should we allow the Michelson-Morley experiment to upset all our primary concepts of physics?" And quoting Magie again, "The principle of relativity accounts for the negative result of the experiment of Michelson and Morley, but without an ether how do we account for the interference phenomena which made that experiment possible?"78 Clearly, like Oliver Lodge, Magie did not think much of the attempt to make relativity and Michelson's work support each other. ${ }^{79}$

In summary, what emerges from explicit historical accounts, including Einstein's interviews with Shankland, is that the story we found earlier in didactic or philosophical resources is, at best, suspect and needs a serious critique. The study so far has served to clarify some of the options that will emerge from direct documentary evidence, first of all from the basic paper by Einstein in 1905.

76 T. W. Chalmers, Historic Researches, p. 81; italics in original.

77 Swenson, “The Ethereal Aether," pp. 280-281 (citing Science, 1912, 35: 287).

78 Ibid., p. 281.

79 Swenson had also further evidence on Michelson's own dismay: "In reply to a request for his own estimates of his most significant achievement, Michelson said: 'I think most people would say that it was the experiment which started the Einstein theory of relativity. That experiment is the basis of Einstein. But I should think of it only as one of a dozen of my experiments in the interference of light waves" (ibid., pp. 317-318, citing James O'Donnell Bennett's article on A. A. Michelson at the age of seventy, The Chicago Tribune, Rotogravure Section, 1923, p. 22). In this connection a passage in Shankland's "Conversations" is relevant: "Michelson said to Einstein that he was a little sorry that his own work had started this "monster" (p. 56). 


\section{Direct Evidence in Einstein's 1905 Paper}

Einstein's paper on relativity of his annus mirabilis of 1905-still so fresh, so clearly the inspired work of genius-has been discussed so often that we need here only a reminder of some chief points. ${ }^{80}$ The purpose of the paper, as implied in the title and the first lines of the introduction, is to provide an electrodynamics of moving bodies, based on the laws previously formulated in Maxwell's electrodynamics for bodies at rest. As Einstein said about forty years later in his "Autobiographical Notes": "The special theory of relativity owes its origin to Maxwell's equations of the electromagnetic fields. Inversely the latter can be grasped formally in satisfactory fashion only by way of the special theory of relativity." 81

The first reason for doing this work is indicated in Einstein's first sentence: "It is known that Maxwell's electrodynamics-as usually understood at the present time-when applied to moving bodies, leads to asymmetries which do not appear to be inherent in the phenomena." This is a dissatisfaction of an aesthetic kind, and incidentally one which shows how modern this work still is. Moreover, as far as one can now tell, the asymmetry to be described, while well known, had not been thought of by other physicists as a major defect that must be remedied. At any rate, we note that Einstein does not start by pointing to some conflict between theory and the known facts. The well-known example he appends to the first sentence is that "the customary view draws a sharp distinction" between the reasons why a current is induced in a conductor when, on the one hand, a conductor is at rest while in the field of a moving magnet (here the current is said to be due to an electric field in the neighborhood of the magnet) and, on the other hand, the conductor is moving in the field of a resting magnet (here no electric field exists in the neighborhood of the magnet, but, following Hertz, an electromotive force appears in the conductor and is responsible for the electric current). Yet the magnitude and direction of the observed currents in the two cases are found to be the same, given the same relative motion. The young author implies that the theory "as usually understood at the present time" is deficient because of the asymmetry of presumed causes, and therefore that a reformulation of electrodynamics is needed to change the "understanding" by removing the asymmetry (as is done later in the paper ${ }^{82}$ ). To be sure, the more

80 Translations which follow are taken largely from Albert Einstein, "On the Electrodynamics of Moving Bodies," pp. 37-65 in The Principle of Relativity, H. A. Lorentz, et al., trans. W. Perrett and G. B. Jeffery (New York: Dover, n.d. [1951]; republication of the translation first published in 1923 of Albert Einstein, "Zur Elektrodynamik bewegter Körper," Annalen der Physik, 1905, 17, with footnotes supplied by A. Sommerfeld). Although I have corrected the translation of several points, none of these corrections changes materially the sense of the translations by Perrett and Jeffery.

\section{3.}

81 Einstein, “Autobiographical Notes," p.

82 Einstein, "On the Electrodynamics of Moving Bodies," pp. 51-55. By requiring that Maxwell's equations be invariant, Einstein shows that a purely electric (or purely magnetic) force field in one system is experienced as an electromagnetic field in another system moving with respect to the first. Hence,

If a unit electric point charge is in motion in an electromagnetic field, the force acting upon it is equal to the electric force which is present at the locality of the charge, and which we ascertain by transformation of 
ordinary scientific paper, particularly in the modern period, is apt to start from some new experimental result or an observation that has been recalcitrant, resisting absorption into the existing theoretical structure.

The example Einstein has chosen is, on the surface, rather pedestrian and not at all novel, going back to Faraday's work. But that is of course the mark of his originality. In leading up to the reformulation of the most fundamental notions of space and time, Einstein does not have to depend on a sophisticated effect or a new or even ancient experimental puzzle. He refers to observations long known and believed to be well understood by everyone. This was also how Galileo argued, in the Dialogue Concerning the Two Chief Systems. So, too, neither Copernicus' De revolutionibus nor Newton's Principia was based on newly available experimental facts; nor was either designed to explain observations which previous theory had failed to accommodate gracefully.

After the details Einstein gave for the case of the induced-current experiment with conductors and magnets, his next two sentences are surprising in their unspecific language and in their combination of apparently unrelated matters:

Examples of this sort, together with the unsuccessful attempts to discover any motion of the earth relatively to the "light medium," suggest that the phenomena of electrodynamics as well as of mechanics possess no properties corresponding to the idea of absolute rest. They suggest rather that, as has already been shown to the first order of small quantities, the same laws of electrodynamics and optics will be valid for all frames of reference for which the equations of mechanics hold good. ${ }^{83}$

We stop briefly at this significant place: It is precisely here that the Michelson experiment might have been referred to. It is, after all, foremost in our textbooks among the experiments on the effects of the earth's motion upon the observed speed of light. But however we may speculate on whether or not Einstein thought about it, his paper does not support such speculation. Again, when Einstein later spoke specifically of the origins of the relativity theory in his "Autobiographical Notes," he failed to mention Michelson's experiment anywhere. Some have found this frustrating, but it would be presumptuous to think that Einstein had any obligation to explain himself on this point, either in 1905 or later. As it will turn out, he did leave more than enough material for the historian to deal adequately with the problem.

What is clear, at any rate, is that the famous experiment is not referred to by name, nor are any other experiments on the presumed effect of the earth's motion relative to the ether. Also, in the sentence referring to the unnamed unsuccessful attempts to discover an ether drift, the experiments are not labeled as

the field to a system of coordinates at rest relative to the electrical charge. . . . We see that the electromotive force plays in the developed theory merely the part of an auxiliary concept, which owes its introduction to the circumstance that electric and magnetic forces do not exist independently of the state of motion of the system of coordinates.
We recall Einstein had said in his Michelson centennial message, "What led me more or less directly to the Special Theory of Relativity was the conviction that the electromotive force acting on a body in motion in a magnetic field was nothing else but an electric field."

83 Ibid., p. 37. 
crucial. They seem to play a supporting role of the following kind: The results of the specified magnet-and-conductor experiments and of the unspecified optical experiments are in conflict with the notions of absolute space and with other ideas of absolutistic physics. Also, in terms of Maxwell's electromagnetic theory, they are closely related experiments. These facts make it that much more reasonable to fasten upon Maxwell's theory as the place where, through its relativization, both optics and electrodynamics must be reinterpreted together.

The suggestion (conjecture, Vermutung) referred to in Einstein's last sentence, whose purport he calls the "principle of relativity," is then, without further discussion, raised in status to become the first of two postulates which form the basis of the rest of the paper. The second postulate (constancy of the speed of light in empty space) is added in the same sentence without citing any evidence which might increase its plausibility. The reader is to find its warrant in the success of the theory based on the postulates.

Table I. Brief schematic structure of the introductory section of Einstein's 1905 paper on relativity

Statements in sequence

A Maxwell's electrodynamics for bodies at rest leads to asymmetries that do not belong to the phenomena.

B

Attempts to discover a motion of the earth relative to the "light aether" have failed.

C Postulation of "principle of relativity" for mechanics, optics, and electrodynamics.

D Postulation of principle of constancy of light speed.

E C $+\mathrm{D}$ will have consequences:
Examples or reasons given

1. Thought experiments à la Faraday on electrodynamic interaction between magnet and conductor.

2. Other "examples of a similar kind" (not specified).

(No examples given.)

1. A $+\mathrm{B}$ "lead to" conjecture (then postulate) C (not shown how).

2. It has already proved useful for first order $(v / c)$ theory.

(No reasons given.)

1. A simple, noncontradictory electrodynamics will result, based on Maxwell's theory.

2. The "light aether" will be superfluous.

Neither here nor later in the paper are the fundamental statements set forth in a logical way, connected to a well-marshalled set of facts and experiments and bolstered by detailed reasons and examples. (See Table I for an attempt to set out schematically the structure underlying these pages of the 1905 paper.) On the contrary, the paper has the freshness of an outpouring of genius that makes it believable it was written within "five or six weeks" (as Einstein wrote to one of his biographers, Carl Seelig, on 11 March 1952) and in a year which saw him send three basic papers off at intervals of less than eight weeks while 
also doing his job at the Bern Patent Office. ${ }^{84}$ It is also quite in accord with Einstein's statement that he had then recently seen "there is no logical way to the establishment of a theory," but that he had to leap over the gap "to the discovery of a universal formal principle." 85

We can thus relate these passages of 1905 with a well-known portion of Einstein's "Autobiographical Notes" (written in 1946, published in 1949), in which he reported on what he regarded to be the origins of relativity theory in his own speculations:

Reflections of this type [on the limitations of Maxwell's theory for the description of pressure fluctuations on a light reflector] made it clear to me as long ago as shortly after 1900, i.e., shortly after Planck's trailblazing work, that neither mechanics nor thermodynamics could (except in limiting cases) claim exact validity. By and by I despaired of the possibility of discovering the true laws by means of constructive efforts based on known facts. The longer and the more despairingly I tried, the more I came to the conviction that only the discovery of a universal formal principle could lead us to assured results. The example I saw before me was thermodynamics. The general principle was there given in the theorem: the laws of nature are such that it is impossible to construct a perpetuum mobile (of the first and second kind). How, then, could such a universal principle be found? After ten years of reflection such a principle resulted from a paradox upon which I had already hit at the age of sixteen: If I pursue a beam of light with the velocity $c$ (velocity of light in a vacuum), I should observe such a beam of light as a spatially oscillatory electromagnetic field at rest. However, there seems to be no such thing, whether on the basis of experience or according to Maxwell's equations. From the very beginning it appeared to me intuitively clear that, judged from the standpoint of such an observer, everything would have to happen according to the same laws as for an observer who, relative to the earth, was at rest. For how, otherwise, should the first observer know, i.e., be able to determine, that he is in a state of fast uniform motion?

One sees that in this paradox the germ of the special relativity theory is already contained. ${ }^{86}$

This passage has its exact parallel in the 1905 paper, in the conceptual leap from a simple experiment (indeed, also a kind of Gedanken-experiment-the relative motion of conductor and magnet) to the general principle from which the content of the relativity theory will derive. Moreover, it appears not to have been noticed before that the seminal paradox pondered in his youth and the experiment in the beginning of the 1905 paper are physically of precisely the same kind: In one case the question concerns the electric and magnetic fields a moving observer finds to be associated with a light beam; in the other case, it concerns the electric and magnetic fields experienced by a moving conductor; and the solutions in both cases follow from the same transformation equations. It seems therefore possible that Einstein may have had this youthful thoughtexperiment with the light beam in mind when he wrote in 1905 the otherwise

84 M. Klein, "Thermodynamics in Einstein's Thought," Science, 1967, 157: 513, writes about this job and quotes Einstein as follows: “. . . contrary to what is sometimes suggested, this job kept him busy-'eight hours of exacting work every day." "

85 Einstein, “Autobiographical Notes," p. 53.

86 Ibid., pp. 51-53. 
rather obscure phrase, "examples of a similar kind." Indeed, the paradox of the light beam would have been a natural bridge to the reference immediately following in the 1905 paper, namely to the experiment attempting "to discover the motion of the earth relative to the "light medium'."

The next sentence of the 1905 paper is one in which Einstein, now near the end of his introduction, almost gratuitously notes a result to be expected from his approach. "The introduction of a 'luminiferous ether' will prove to be superfluous inasmuch as the views here to be developed will not require an 'absolutely stationary space' provided with special properties. . . " This quickly brings him to the "Kinematical Part" with its examination of the concepts of space and time. The Lorentz transformation equations are derived from the postulates and lead to the transformation of the Maxwell-Hertz equations that encompass all electrodynamic phenomena, including moving magnets at one end and moving light beams at the other. All the rest follows from this: the relativistic Doppler effect, aberration, and the pressure of radiation exerted on a reflector. It is significant that aberration and change in frequency of a light wave are the two oldest known optical effects due to the motion of the earth relative to the stars-known long before the Michelson experiment-and that the problem of radiation pressure is one which Einstein reported later to have intrigued him very early as evidence of the limits of applicability of Maxwell's theory.

But at this point Einstein stops himself: "All problems in the optics of moving bodies can be solved by the method here employed. What is essential is, that the electric and magnetic force of the light which is influenced by a moving body, be transformed into a system of co-ordinates at rest relatively to the body." (Here the experiment of the magnet and induced current connects again with the experiment on the light beam.) "By this means all problems in the optics of moving bodies will be reduced to a series of problems in the optics of stationary bodies." 87

It would be incredible for a more ordinary physicist, particularly for a young man proud to show the power of his new theory, to do what Einstein now does (or does not do): He fails to explain that these sentences contain a reinterpretation of the null result of the Michelson experiment, the relativistic equivalent of the Lorentz-FitzGerald contraction, and the solution of other problems that had preoccupied many of the best physicists during the previous two decades. Depending on one's predisposition, the last sentence cited above can be interpreted as a statement of elegance, of arrogance, of ignorance of the detailed experiments in the "optics of moving bodies," of lack of serious concern with the messy details of experimental physics, or even of mere lack of time to go into further detail in a thirty-one-page paper, written rapidly during an immensely productive period.

I suspect that all of these elements were at work, but the first is the most prominent. For example, in forgoing for the second time the opportunity to mention the Michelson experiment, Einstein is only facing the fact that from the

87 Einstein, “On the Electrodynamics of Moving Bodies," p. 59. 
point of view of relativistic physics, nothing important happens at all in the experiment. The result is "natural," fully expected, and trivially true. The abandonment of the ether and the acceptance of the transformation equations meant the disappearance of both the objective and the very vocabulary for discussing the ether-theoreticians' interests in the null result and in the possible "causes" of the "contraction." The two views of the experiment were thus different to the point of being unbridgeable, which accounts for the inconclusiveness of debates between the two factions long after the paper was published, for example at the 1927 meeting on the Michelson experiment. The relativists simply could not see the complex problems that were seriously evident to the ether theorists to whom, in Dugas' happy phrase, the ether still formed "the substratum of thought in physics."

This recognition should prepare us for the possibility that analogous philosophical differences separate the two points of view on the overriding question - how to understand the history of the development of relativity theory. On one hand is the largely intuitive, wholistic approach of Einstein himself, with some empiricist and rationalist elements; on the other hand, there are the axiomatic and experimenticist approaches we noted earlier. To the first group it appears natural that an experiment that played no decisive role should not be mentioned; for the second group, however, the absence in Einstein's paper of specific acknowledgments to the role of Michelson's experiment becomes a problem, and Einstein is seen as having shirked an "obligation" to explain himself. ${ }^{88}$

Returning to Einstein's paper of 1905, we find at the end a short section on the dynamics of moving electrons-that particularly famous case of moving bodies discovered only eight years earlier, and concurrently the subject of widely discussed experiments, such as those by Kaufmann. None of the experiments, however, is mentioned. The paper ends with three statements, one of which "may be tested experimentally," and which together are boldly summarized as "the laws according to which, by the theory here advanced, the electron must move." 89 This is in fact the only place in the paper where new experimental results are predicted explicitly, although elsewhere there are a few implications, for example, that an object moving at high relative speeds "will appear shortened" and that a moving clock will appear to a stationary observer to keep time more slowly. In a few instances a result is said to be in accord with established experiments (the case of the pressure of light, for instance). Yet, while Einstein develops the equations which can explain with striking ease such historic experiments as the Fizeau test of Fresnel's theory of ether drag or the aberration observations, the equations are not explicitly applied to them.

In a paper meant to be read by a community of scientists used to being presented with experimental verification of new theories, it would have greatly

88 Grünbaum, Philosophical Problems of Space and Time, p. 380.

If the history of ether theory itself is a guide, one may predict that on this issue, as on others, few of the protagonists can be expected to change their minds, owing to the stability of the "substratum of thought," the thematic presuppositions.

89 Einstein, "On the Electrodynamics of Moving Bodies," p. 65. 
helped the establishment of relativity theory if there had been, so to speak, a pedagogic section elaborating on the consequences of the basic work. One can only speculate that this remarkable omission may be additional evidence that the author perceived as obvious what to others would be a delighted discovery, and that he was single-mindedly attending to his announced main purpose- the reformulation of electrodynamics based on Maxwell's equations, together with the reform of the notions of space and time which this work necessitates. ${ }^{90}$

By his own, later criteria for a sound theory- "internal perfection" and "external confirmation"11 one might have expected a little more detailed discussion of both. However, the paucity of cited "facts" and experiments conforms to Einstein's dictum of what constitutes "external confirmation": Not that a theory must be built on clearly visible empirical facts; not that the theory must be verified by decisive experimentation; but rather, "The theory must not contradict empirical facts." ${ }^{2}$ This criterion is even coupled with a warning against trying to secure "the adaptation of the theory to the facts by means of artificial additional assumptions" such as are "often, perhaps even always, possible." ${ }^{33}$ This remark led Einstein to discuss the criteria concerning the premises of a theory, "with what may briefly but vaguely be characterized as the 'naturalness' or 'logical simplicity' of the premises." He admits that "an exact formulation . . . meets with great difficulties," for it involves "a kind of reciprocal weighing of incommensurable quantities." Though he cannot be more precise, "it turns out that among the 'augurs' there usually is agreement in judging the 'inner perfection' of theories. . . " 94 Here we face again the role of what can only be called scientific taste in deciding which theory or hypothesis to accept and which to reject. We shall come back to this important point later.

To summarize: The style of thought that emerges from the direct examination of the 1905 paper is fully consonant with Einstein's report half a century later on the occasion of the centennial of Michelson's birth. It is not a theory of the more usual kind, designed to save one or even a few phenomena, but a theory "whose object is the totality of all physical appearances." 95 There is nothing in the paper which gives support to the idea that Einstein must have considered Michelson's experiment as crucial or even of primary importance, or even that he did know or had to know of its existence. Michelson's null result is evident "on other grounds" if one accepts the general sway of Maxwell's theory over all electrodynamics and optics and applies the relativity principle to it. Such basic

90 As Einstein stated (cited by Max Born, "Physics and Relativity," in Helvetica Physica Acta, Supplementum IV, 1956: 248):

The new feature of it [the work of 1905] was the realization of the fact that the bearing of the Lorentz-transformations transcended their connection with Maxwell's equations and was concerned with the nature of space and time in general. A further new result was that "Lorentz invariance" is a general condition for any physical theory. This was for me of par- ticular importance because I had already previously found that Maxwell's theory did not account for the micro-structure of radiation and could therefore have no general validity. ... . 23.

91 Einstein, “Autobiographical Notes," p.

92 Ibid., p. 21; italics added.

93 Ibid., pp. 21-23.

94 Ibid., pp. 23-25.

95 Ibid., p. 23. 
experimental results as are assumed in the paper could well be those of Faraday, Fizeau, and the aberration experiments. From first to last Einstein's paper is a work on a grandiose scale, specifically intended to transform the electrodynamic theory as then understood; and in the process it implies its own methodology and its own metaphysics to serve as the philosophical basis of a renewed science. This is of course why we think of it still as so powerful a work.

\section{Indirect Evidence: From 1905 and Earlier}

We have seen no direct evidence in the 1905 paper itself to support the common textbook story, and on the contrary we have found more plausible evidence in the opposite direction. However, this cannot by any means complete our search, for there are a number of different types of indirect evidence to be examined, including evidence from contemporaneous work of Einstein in 1905 and from his early work, comments, and letters.

Reading other work by Einstein in 1905, we may expect to find additional insight into his assessment of the relation between experimental fact and theory. As I have discussed elsewhere, ${ }^{96}$ the three epochal papers of Einstein published in 1905, though on such very different fields of physics-quantum theory of light, Brownian motion, relativity - all shared two significant properties. They arose from the same general problem: fluctuations in radiation pressure, for which in the case of a mirror suspended in a radiation cavity Einstein knew by 1905 that Maxwell's theory leads to wrong predictions. And they shared the same style of construction: "Each begins with the statement of formal asymmetries or other incongruities of a predominandly esthetic nature ...., then proposes a principle - preferably one of the generality of, say, the second law of thermodynamics, to cite Einstein's repeated analogy-which removes the asymmetries as one of the deduced consequences, and at the end produces one or more experimentally verifiable predictions." 97

The experimental part in each of the three papers was by far the least developed and for many the most unconvincing part. Thus, Millikan, whose Nobel prize in physics was awarded in part for his experimental confirmation of Einstein's theory for the photoelectric effect, remarked later that Einstein's explanation of the effect in 1905

at the time ignored and indeed seemed to contradict all the manifold facts of interference and thus to be a straight return to the corpuscular theory of light which had been completely abandoned since the time of Young and Fresnel around 1800 A.D. I spent 10 years of my life testing the 1905 equation of Einstein's, and, contrary to all my expectations I was compelled in 1915 to assert its unambiguous experimental verification in spite of all its unreasonableness since it seemed to violate everything that we knew about the interference of light.98

We conclude that Einstein's other work of 1905 was quite consistent with the relativity paper, and that in particular the attitude toward experiments was the

${ }^{96}$ Holton, "On the Origins of the Special Theory of Relativity," pp. 629-630. 97 Ibid., p. 629.
98 Millikan, "Albert Einstein on His Seventieth Birthday," p. 344. 
same: reliance on a very small number of experiments either as the basis of the theory or as a support to its claim to serious attention.

Elsewhere I have shown that at least from 1907 on we have evidence that even in the case of "disconfirming facts," such as Kaufmann's confident "experimental disproof" of relativity in 1906, Einstein continued to believe in a theory that seemed to him to have a "greater probability" because it embraced a "greater complex of phenomena." 99 I shall now set forth, in approximately chronological order, the other documents I have been able to find that have a bearing on Einstein's attitude on the importance of experimentation, particularly with respect to the Michelson experiment.

There is good evidence that as a young student Einstein regarded himself an empiricist. The later attainment of a more complex position was definite enough to be dated by Einstein himself in his "Autobiographical Notes" as "shortly after 1900," when he found after Planck's publications of 1900 that neither mechanics nor thermodynamics could claim exact validity. "By and by I despaired of the possibility of discovering the true laws by means of constructive efforts based on known facts." ${ }^{100}$ But prior to that, while a student at the Polytechnic Institute of Zürich from 1896 to 1900, he tended toward practical experimentation: "There I had excellent teachers (for example, Hurwitz, Minkowski), so that I really could have gotten a sound mathematical education. However, I worked most of the time in the physical laboratory, fascinated by the direct contact with experience." 101 This dating fits with evidence provided in 1930 by Einstein's biographer Anton Reiser, ${ }^{102}$ who, as I have pointed out elsewhere, ${ }^{103}$ was in fact Einstein's son-in-law, Rudolf Kayser, who worked on the biography with Einstein's acquiescence. An interesting passage in the biography refers to young Einstein's early interest in constructing by himself an experiment of the type we have been here discussing, while under the sway of "pure empiricism":

$\mathrm{He}$ encountered at once, in his second year of college, the problem of light, ether and the earth's movement. This problem never left him. He wanted to construct an apparatus which would accurately measure the earth's movement against the ether. That his intention was that of other important theorists, Einstein did not yet know. He was at that time unacquainted with the positive contributions, of some years back, of the great Dutch physicist Hendrik Lorentz, and with the subsequently famous attempt of Michelson. He wanted to proceed quite empirically, to suit his scientific feeling of the time, and believed that an apparatus such as he sought would lead him to the solution of a problem, whose far-reaching perspectives he already sensed.

But there was no chance to build this apparatus. The skepticism of his teachers was too great, the spirit of enterprise too small. Albert had thus to turn aside from his plan, but not to give it up forever. He still expected to approach the major questions of physics by observation and experiment. His thought was most intensely bound up with reality. As a natural scientist he was a pure empiricist. He

99 Holton, "Mach, Einstein, and the Search for Reality," esp. pp. 651-653. 53.

100 Einstein, "Autobiographical Notes," p.

101 Ibid., p. 15.
102 Anton Reiser, Albert Einstein

York: Albert and Charles Boni, 1930).

$103 \mathrm{G}$. Holton, "Influences on Einstein's Early Work in Relativity Theory," American Scholar, Winter 1968-1969, 37: 59-79. 
did not entirely believe in the searching power of the mathematical symbol. After several years this state of affairs changed completely. ${ }^{104}$

The story fixes a date (the academic year 1897-1898) before which Einstein would not have heard of the Michelson experiment, and it helps us also to understand what otherwise may seem to be puzzles and contradictions in Einstein's references to his state of knowledge of the Michelson experiment prior to the publication of the 1905 paper. It makes it that much more believable that Einstein could have accepted without surprise the result of the Michelson experiment when he did become aware of it, for he had pondered about an ether-drift experiment of his own; and at any rate his empiricist type of approach had later "changed completely." As we noted from Shankland's first interview with Einstein in 1950, "when I asked him how he had learned of the Michelson-Morley experiment, he told me that he had become aware of it through the writings of $\mathrm{H}$. A. Lorentz, but only after 1905 had it come to his attention!"105 And in 1952 Einstein told Shankland, "I am not sure when I first heard of the Michelson experiment. I was not conscious that it had influenced me directly during the seven years that relativity had been my life. I guess I just took it for granted that it was true."106 Shankland immediately adds, "However, Einstein said that in the years 1905-1909, he thought a great deal about Michelson's result, in his discussions with Lorentz and others in his thinking about general relativity. $\mathrm{He}$ then realized (so he told me) that he had also been conscious of Michelson's result before 1905 partly through his reading of the papers of Lorentz and more because he had simply assumed this result of Michelson to be true."

Shankland's report of Einstein having read "Lorentz's papers" before 1905 must now be clarified. We know such reading in fact did not include the famous 1904 paper of Lorentz, ${ }^{107}$ in which he gave his theory of electromagnetism for moving bodies to quantities of the second order $\left(v^{2}: c^{2}\right)$, nor probably most of the other papers that partly had prepared for it. ${ }^{108}$ We have positive evidence of Einstein having read only one paper and one book by Lorentz-the paper of 1892 (published in French) and the book of 1895 (published in German), in which the theory given is to the first order of the quantity $(v: c)$. This fits entirely with Einstein's remark in the 1905 paper, "as has already been shown to the first order of small quantities. . ." Also, Einstein wrote specifically on this point to his last biographer, Carl Seelig: “As for me, I knew only of Lorentz's important work of 1895-'La théorie électromagnétique de Maxwell' [actually published in 1892], and 'Versuch einer Theorie der elektrischen und optischen Erscheinungen in bewegten Koerpern' [1895]—but not Lorentz’s later publication, nor the consecutive investigations by Poincaré. In this sense my work of 1905 was independent." ${ }^{109}$ We may well take Einstein's quoted word to Seelig;

104 Reiser, Albert Einstein, pp. 52-53.

105 Shankland, "Conversations," p.

italics in original.

106 Ibid., p. 55.

107 H. A. Lorentz, "Electromagenetic Phenomena in a System Moving with any Velocity Smaller than that of Light," Proceedings

of the Academy of Sciences, Amsterdam, 48; 1904, 6: 809 .

108 The fact that most of these papers seem to have been difficult to obtain and were published in Dutch or English may play a role here.

109 Cited by Born, "Physics and Relativity," 
and even if he had read other papers by Lorentz prior to Lorentz's 1904 paper, he would not have found in them a more extensive discussion of the Michelson experiment than Lorentz gave in his 1895 book. It will therefore be profitable if we look with a little care at Lorentz's 1895 work. ${ }^{110}$

In this work Lorentz is still satisfied with the construction of a theory which will explain first-order effects, that is, quantities in $v: c$. Therefore the Fresnel ether theory and the aberration experiment are prominently mentioned on page 1 and are further dealt with in the text. But the Michelson ether-drift experiments are only briefly mentioned (on p. 2) with the casual warning that they will find interpretation in the framework of a first-order theory only by means of what he calls a Hülfshypothese. The matter is not brought up again until page 120, in a short section toward the end of the 139-page book. This, however, has become that part of the book which everyone in the field knows, because the particular excerpt-with its subtitle "Michelson's Interference Experiment" now serving as the main title-was put at the beginning of the famous reprint collection of Lorentz, Einstein, Minkowski, and Weyl, published by Teubner in 1913. ${ }^{111}$ (Thus do scissors-wielding and extract-prone editors distort the appearance of history!)

In Lorentz's book this section appears in the last chapter, one devoted to residual difficulties to Lorentz's otherwise quite successful first-order theory, and is entitled "Experiments whose Results do not allow Explanation without Further Ado." He discusses three such embarrassing experiments. The first takes about five pages and is on an unexpectedly absent rotation of the plane of polarization (Mascart, 1872), which Lorentz attempts to explain by a separate ad hoc hypothesis without much conviction. Then come the 1881 and 1887 ether-drift experiments of Michelson (also in about five pages). There, on "the basis of Fresnel's [ether] theory," a $v^{2}: c^{2}$ effect was predicted. To explain why it had

p. 248. The book of Lorentz, Versuch einer Theorie der elektrischen und optischen Erscheinungen in bewegten Koerpern, was published by E. J. Brill, Leyden, 1895 (reprinted in 1906 without change by Teubner, Leipzig).

As I have shown elsewhere ("Influences on Einstein's Early Work in Relativity Theory") in almost all the books from which Einstein may have learned Maxwell's theory the Michelson experiment was not even mentioned -neither in the lectures on Theoretical Physics by Helmholtz, although it was in his own laboratory that Michelson's first experiment had been begun, nor in Hertz's essays, nor in August Föppl's Maxwells Theorie der Elektrizität. In fact, the most significant point about the German treatises is that there is a remarkable paucity of references to actual experimental situations, not only to Michelson's, but also to all other ether-drift experiments. One clear exception is P. Drude's Lehrbuch der Optik (Leipzig: S. Hirzel,
1900; issued in 1901 as The Theory of Optics, trans. C. R. Mann and R. A. Millikan, preface by A. A. Michelson, London: Longmans \& Green). But the discussion of the optical properties of moving bodies is based entirely on Lorentz's Versuch of 1895, which has "developed a complete and elegant theory. It is essentially this theory which is here presented" (p. 457, English translation). Thus in discussing an explanation of the Michelson experiment in terms of the contraction hypothesis Drude copies almost word for word the corresponding sentences from Lorentz's Versuch.

110 A brief draft of the next few pages was presented in the Proceedings of the International Conference on Relativistic Theories of Gravitation, Vol. I (London, 1965), pp. 14-18 (mimeographed edition).

111 Das Relativitätsprinzip (Leipzig/Berlin: Teubner, 1913). The collection has been often reprinted and exists in English translation as The Principle of Relativity, op. cit. 
not been observed, Lorentz first rejects Stokes' original aberration theory as one that raises too many difficulties; as an alternative he will try to obtain the removal of the puzzle "by means of a hypothesis which I have already announced some time ago [in 1892-1893] and which, as I later found, FitzGerald reached also." This saving Huilfshypothese is introduced completely ad hoc: "If one assumes that the arm [of the interferometer] lying in the direction of the earth's motion is shorter than the other by $L\left(v^{2}: c^{2}\right) \ldots$, the result of the Michelson experiment is fully explained." 112 He acknowledges that "this hypothesis at first glance may appear estranging [befremdend], but one must nevertheless admit that it is not so far-fetched" if one associates it with yet another assumption, namely that the molecular forces that determine the dimensions of a body are modified by relative ether motion, "similar to what may now be certainly stated for electric and magnetic forces."

No explicit comment is made which connects this assumed shrinkage with the Lorentz transformations in their still primitive form, as published earlier in the book. And throughout this section Lorentz stresses the ad hoc nature of the argument. Thus when he comes back to the equality of transformation properties he has assumed for both the molecular forces and electrostatic forces, he confesses there is "no ground" for the assumption. ${ }^{113}$ The reader is left with the impression that the results of this experiment indeed "sich nicht ohne Weiteres erklaeren lassen," as the title of the chapter warned. It appears therefore that the whole work would not have been adversely affected if the Michelson experiment had not been done at all!

The third experiment Lorentz takes up in this 1895 book is the polarization experiment of Fizeau on glass columns, in which Fizeau had thought to have detected an effect of the earth's motion on the plane of polarization of light. These are the final thirteen pages of the book and therefore the longest of the three items. This experiment is singled out by Lorentz's remarks that its results "deserve our attention in high measure."114

So when Einstein mentions in 1905, after the opening paragraph of his relativity paper, "the unsuccessful attempts to discover any motion of the earth relative to the "light medium," "without naming specifically any one of them, he could have had in mind any two or more of at least seven experiments-the first two which were cited in the last chapter of Lorentz's work of 1895 and five additional ones that became known by 1905: the experiments by Rayleigh of 1902 on rotary polarization and double refraction; by Brace on double refraction in 1904 and the repetition, with negative effect, of the Fizeau experiment on glass columns in 1905; and by Trouton and Noble in 1903 on the turning couple of a condensor. (One might also add other ether experiments which had a bearing: e.g., Arago, 1810; Fizeau, 1851; Lodge, 1892.) Pointing out that Einstein had all these choices, as is clear to anyone who has read the available literature, does not

112 Lorentz, Versuch einer Theories der elektrischen und optischen Erscheinungen in bewegten Koerpern, p. 123.

113 "Wozu freilich kein Grund vorliegt" (ibid., p. 124).

114 It turned out that Fizeau's experimental results were erroneous, as Lorentz had in effect begun to suspect (ibid., pp. 2, 127). 
in itself deny the possibility of an inspirational role for the Michelson experiment. On the other hand, there is also no warrant for believing that Einstein's phrase "the unsuccessful attempts" must point directly to any one of these experiments, including Michelson's. It is in fact entirely possible that he had heard and read about any two of these "unsuccessful attempts" and had drawn the correct conclusion that all of them would be unsuccessful.

We turn now briefly to Lorentz's basic 1904 paper, which everybody, including Einstein after 1905, read and cited. Lorentz there forges ahead with the improvement of the first-order theory of 1895 and specifically tries to reach a theory to cover second-order phenomena. The Michelson experiment is therefore much more important to Lorentz's argument than it was in 1895. It now appears at the very beginning of the paper, followed by some of the other more recent, embarrassing experiments (Rayleigh, Brace, Trouton and Noble, and Kaufmann), and the explanation of Michelson's results is given at two different places. ${ }^{115}$ It is a masterful paper. In my opinion it is, together with Poincarés paper of 1905, the best work prior to Einstein's relativity theory that electrodynamics was capable of achieving. But it is significant that in this peak achievement of classical physics we find two striking flaws, both later acknowledged by Lorentz himself.

The first is that the transformation equations Lorentz developed here do not after all achieve what he had hoped: Maxwell's equations are not completely invariant even at small speeds. In 1912 Lorentz generously added a footnote to the 1913 republication of his 1904 paper in the Teubner collection, one that was unfortunately left out in the English-language reprint of the essay:

One will notice that in this work the transformation equations of Einstein's Relativity Theory have not quite been attained. Neither equation (7) nor formula (8) has the form given by Einstein, and as a result I was unable to make the term $-w u_{\mathrm{x}}^{\prime} / c^{2}$ in equation (9) disappear and to put equation (9) exactly in the form which holds for a system at rest. On this circumstance depends the clumsiness [Unbeholfene] of many of the further considerations in this work. It is owing to Einstein that the relativity principle was first announced as a general, strictly and exactly valid law. ... .116

In Lorentz's The Theory of Electrons we find a similar statement. ${ }^{117}$ Lorentz points out that "besides the fascinating boldness of its starting point, Einstein's theory has another advantage over mine." Einstein has attained exact covariance "by means of a system of new variables slightly different from those which I have introduced." And Lorentz adds significantly: "I have not availed myself of his substitutions, only because the formulae are rather complicated and look somewhat artificial, unless one deduces them from the principle of relativity itself." This remark incidentally serves to announce the theme of the relativity of "artificial" assumptions, to be discussed below in more detail. ${ }^{118}$

115 The Principle of Relativity, pp. 22, 29. 116 Das Relativitätsprinzip, p. 10.

117 H. A. Lorentz, The Theory of Electrons (Leipzig: Teubner; New York: Stechert, 1909); 2nd ed. (Teubner, 1915), p. 230.
118 Professor C. Kittel has pointed out to me that Joseph Larmor's book Aether and Matter (Cambridge: Cambridge Univ. Press, 1900), which neither Einstein nor Lorentz cites, sets forth the complete and exact 
The recognition of a second flaw in Lorentz's work, one that now strikes us as even more serious than the first, is implied in another typically generous comment by Lorentz in 1909 in The Theory of Electrons. There he hints at a further aspect of the difference between the "clumsiness" of his own hypothesis-ridden, constructive theory and the "fascinating boldness" of Einstein's approach, which sweeps away the whole complex machinery of ether-electrodynamics, a theory in which Einstein started from general principles and jettisoned wherever possible any assumption, even one that was as precious to contemporary physics as the light ether. Einstein's results concerning electromagnetic and optical phenomena, Lorentz writes,

... agree in the main with those which we have obtained in the preceding pages, the chief difference being that Einstein simply postulates what we have deduced, with some difficulty and not all together satisfactorily, from the fundamental equations of the electromagnetic field. By doing so, he may certainly take credit for making us see in the negative results of experiments like those of Michelson, Rayleigh, and Brace, not a fortuitous compensation of opposing effects, but the manifestation of a general and fundamental principle. ${ }^{119}$

In a note added in the edition of 1915 Lorentz went further: “. . . Einstein's theory . . . gains a simplicity that I had not been able to attain."120 Einstein agreed in a publication soon afterward, stating that the relativity theory grew out of the Maxwell-Lorentz theory of electrodynamics "as an amazingly simple summary and generalization of hypotheses which previously had been independent from one another. ..."121 This feeling of attaining a view in which previously separate processes, phenomena, or mechanisms now appear interdependent has always been a quasi-aesthetic experience of the most treasured kind in the sciences. One is reminded of Copernicus' triumphant boast in the De revolutionibus that in his heliocentric system "not only do all their [the planets'] phenomena follow from that, but also this correlation binds together so closely the order and magnitudes of all the planets and of their spheres or orbital circles, and the heavens themselves, that nothing can be shifted around in any part of them without disrupting the remaining parts and the universe as a whole."

Lorentz transformation equations for $x, t, E$, and $B$. Larmor claimed it only to the order of $(v / c)^{2}$, which is all he needed and used to explain the null result of the MichelsonMorley experiment; but since he was trying to make $x^{2}-c^{2} t^{2}$ invariant, as we do today, Larmor got the whole transformation exactly.

One of Larmor's erstwhile students, E. Cunningham, in a letter of 14 Dec. 1963 to Kittel, explained that he did not notice the exactness of the transformation in 1903-1904, but thought, like Lorentz, he had it only to second order. Therefore, he spoke of it as the Larmor-Lorentz transformation. In 1904 he moved from Cambridge to Liverpool, discovered there the exactness, and wrote to Larmor, who replied briefly he knew it, though he had not referred to it in publica- tion or lecture. Cunningham adds simply: "Larmor did not seem at all enthusiastic about the idea that an algebraic transformation happened to be exact." One is reminded of Lorentz's disinclination to assign a more general meaning to the concept of Ortszeit. It is an interesting sidelight on the limitation which can be put on a theory if it is seen as serving immediate purposes.

119 Lorentz, The Theory of Electrons (1909), p. 230. Lorentz and Einstein came to be close friends, each admiring the scientific contributions of the other despite their fundamentally different approaches to electrodynamics.

120 Ibid. (1915), p. 321.

121 Über de spezielle und die allgemeine Relativitätstheorie, p. 28. 


\section{ViII. Against an Ad Hoc Physics}

That feeling of having unveiled a grand scheme, one so beautifully interconnected that all of it can be entered through a very small set of postulates, is precisely what seems lacking in Lorentz's theory. Devoted though Poincaré was to Lorentz, he reserved some of his most caustic criticism for the way more and more new hypotheses appeared in this work:

On a fait des expériences qui auraient dû déceler les termes du premier ordre; les résultats ont été négatif; cela pouvait-il être par hasard? Personne ne l'a admis; on a cherché une explication générale, et Lorentz l'a trouvée; il a montré que les termes du premier ordre devaient se détruire, mais il n'en était pas de même de ceux du second. Alors on a fait des expériences plus précises; elles ont aussi été négatives; ce ne pouvait non plus être l'effet du hasard; il fallait une explication; on l'a trouvée; on en trouve toujours; les hypothèses, c'est le fonds qui manque le moins.

Mais ce n'est pas assez. . . ."122

Lorentz surely did not enjoy the ad hoc character of his theory. The matter was evidently much on his mind when he wrote the 1904 paper. On the second page Lorentz gives the chief reasons for publishing a new treatment:

The experiments of which I have spoken are not the only reason for which a new examination of the problems connected with the motion of the Earth is desirable. Poincaré has objected to the existing theory of electric and optical phenomena in moving bodies that, in order to explain Michelson's negative result, the introduction of a new hypothesis has been required, and that the same necessity may occur each time new facts will be brought to light. Surely this course of inventing special hypotheses for each new experimental result is somewhat artificial. It would be more satisfactory if it were possible to show by means of certain fundamental assumptions and without neglecting terms of one order of magnitude or another, that many electromagnetic actions are entirely independent of the motion of the system. Some years ago [1899], I already sought to frame a theory of this kind. I believe it is now possible to treat the subject with a better result. . . . ${ }^{123}$

\section{There is little doubt that Lorentz's hopes for a more satisfactory theory were}

$122 \mathrm{H}$. Poincaré, Congrès de physique de 1900 (Paris), 1: 22.

123 The Principle of Relativity, pp. 12-13. An example of Lorentz's sensitivity to this issue was shown in an article in the Acta Mathematica, 1912, 38, reprinted at the end of Vol. IX of Poincaré's Euvres (Paris: Gauthier-Villars, 1954), in which Lorentz gives an assessment of the contribution of Poincaré to physics, particularly to relativity theory and quantum theory. And on that occasion Lorentz allowed himself a word of regret about his own method of procedure (p. 684):

In order to explain Michelson's 1881 experiment, the hypothesis of an immobile ether was not sufficient. I was obliged to make a new supposition which had the effect of admitting that the translation of a body through the ether produced a slight contraction of the body in the direction of motion. This hypothesis was the only one possible. It had been imagined by FitzGerald, and it found acceptance by Poincaré; but Poincaré nevertheless did not hide how little satisfaction was given to him by theories in which one multiplies special hypotheses invented for particular phenomena. This criticism was for me one more reason to search for a general theory. . . .

For more on Poincaré's dissatisfaction with the hypotheses then needed, see C. Scribner, "Henri Poincaré and the Principle of Relativity," Am. J. Phys., 1964, 32: 672, and S. Goldberg, "Henri Poincaré and Einstein's Theory of Relativity," Am. J. Phys., 1967, 35: 934-944. 
not entirely in vain. Thus he could say "the only restriction as regards the velocity will be that it be less than that of light."124 But the work is far from dispensing with the need to set up "special hypotheses" to explain new experimental results, and Lorentz has to introduce explicitly or implicitly at least eleven different ad hoc assumptions or hypotheses (the terms are used interchangeably in his paper), as I have pointed out previously. ${ }^{125}$ For a paper that is to deal with physics from a fundamental point of view it is veritably obsessed with hypotheses. I have made a quick count of the number of times the term "hypothesis" or "assumption" and their direct equivalents ("I shall now suppose") appear: It happens at least thirty times in these pages and even more if one adds circumlocutions and implicit references (e.g., "the velocity will be subjected to a limitation ..."). Whether all the hypotheses introduced are ad hoc in the same sense or to the same degree, whether the criteria of ad hocness are different for different types of theory, or whether such distinctions are significantly meaningful for physicists or philosophers are not issues at this point. What is more relevant for an understanding of Einstein's work is to read Lorentz's paper through the eyes of someone such as Einstein whose style of work is to minimize the making of hypotheses.

On the other hand, to appreciate Lorentz's purpose and problem fully we must remember that he saw the crisis of physics in the 1890's and 1900's in a rather different way from Einstein. With his immense knowledge in virtually every part of physics, Lorentz was then particularly deeply involved in constructing, step by step, a viable theory for electrodynamics, based as far as possible on existing principles and mechanisms, relying on experimental results as a guide to the detailed construction of a modification of existing theory. The result, as a careful reading of Lorentz's papers shows, was that Poincaré's accusation was all too justified. But Lorentz was attending to a very difficult problem with conventional tools, and today we also know how to live in some areas of contemporary physics with far less elegant work and more blatantly ad hoc hypotheses. Nothing better could probably be done as long as the ether was kept at the heart of physics; and that seemed to Lorentz, as to Poincaré, Michelson, and many others, a thematic necessity to the end of his life. ${ }^{126}$

The simplification introduced by Einstein's approach is far easier to discern with hindsight. The decisions at this point in the origins of contemporary science were quite analogous to the decisions at the fork in the road to modern sciencein accepting or rejecting the Copernican system in the sixteenth century. A famous passage in Herbert Butterfield's The Origins of Modern Science is as appropriate for the twentieth-century turning point as for the earlier one:

... at least some of the economy of the Copernican system is rather an optical illusion of more recent centuries. We nowadays may say that it requires smaller effort to move the earth round upon its axis than to swing the whole universe in a

124 The Principle of Relativity, p. 13.

125 Holton, "On the Origins of the Special Theory of Relativity," p. 630.
126 See G. Holton, "On the Thematic Analysis of Science: The Case of Poincaré and Relativity," Mélanges Alexandre Koyré (Paris: Hermann, 1964), pp. 797-800. 
twenty-four hour revolution about the earth; but in the Aristotelian physics it required something colossal to shift the heavy and sluggish earth, while all the skies were made of a subtle substance that was supposed to have no weight, and they were comparatively easy to turn, since turning was concordant with their nature. Above all, if you grant Copernicus a certain advantage in respect of geometrical simplicity, the sacrifice that had to be made for the sake of this was tremendous. You lost the whole cosmology associated with Aristotelianism-the whole intricately dovetailed system in which the nobility of the various elements and the hierarchical arrangement of these had been so beautifully interlocked. In fact, you had to throw overboard the very framework of existing science, and it was here that Copernicus clearly failed to discover a satisfactory alternative. He provided a neater geometry of the heavens, but it was one which made nonsense of the reasons and explanations that had previously been given to account for the movements in the sky. ${ }^{127}$

Here again a similar agonizing choice had to be made: In order to extend the principle of relativity from mechanics (where it had worked) to all of physics, and at the same time to explain the null results of all optical and electrical etherdrift experiments, one needed "only" to abandon the notion of the absolute frame of reference and with it the ether. But without these the familiar landscape changed suddenly, drastically, and in every detail. Physics was left without its old hope, already partly and sometimes gratifyingly fulfilled, namely to explain all phenomena by means of one consistent, mechanistic theory.

In the compass of this work we cannot do full justice to the question of what constitutes an ad hoc hypothesis as it affects the work of scientists such as Lorentz and Einstein; but we must at least include some comment, for it is an essential issue for two related reasons. Somewhat along the line of the textbook story, a few philosophers of the experimenticist persuasion appear to think that Lorentz's and Poincarés theory was on the whole satisfactory (e.g., they argue that not all the hypotheses were ad hoc in the same sense or that Einstein's theory did not drastically reduce the number and artificiality of the needed hypotheses), so that the Michelson experiment becomes more plausibly the "crucial" event that forces a radical reconsideration. More important for our purposes is another reason for clarifying the meanings of ad hoc in the actual work of scientists: to be able to appreciate the differences of style between the chief protagonists and indeed the differences between classical nineteenth-century physics and modern twentieth-century physics.

To begin with, operationally it does not matter much whether an ad hoc hypothesis appears to have some support in theory (thus it is easily seen from Lorentz's papers that he tried to link the contraction hypothesis with the supposedly analogous behavior of "molecular forces" on the one hand and electric and magnetic forces on the other, though without being able to say anything revealing about these presumed molecular forces). It also does not much matter that the contraction hypothesis was not completely self-contained; Lorentz him-

127 Herbert Butterfield, The Origins of Modern Science (New York: Free Press, $1957)$, p. 41. Copernicus was variously regarded as a madman, a fool, or a genius. The description that fits best is not found by examining the logical processes evident in his publications. 
self made clear that his ad hoc assumptions might have uses beyond merely explaining the experiments that forced their invention (e.g., the prediction of a negative result for the Michelson experiment for light rays traversing transparent objects). ${ }^{128}$ These other applications of the ad hoc hypothesis are not of real interest in any case; they were not urged as tests that would decide on its acceptability, and even if such tests had been carried out successfully, it is unlikely that they would have increased the appeal of the hypothesis to Einstein.

A refinement of the concept of ad hoc, including divisions into such categories as "logically ad hoc" and "psychologically ad hoc," may perhaps be of interest for epistemological discussions. Such work, however, has yet to make a really important point, and at any rate we must not draw attention away from what is an important point, namely the scientist's feeling of ad hocness about an hypothesis, whether his own or not-for example, the distaste for the contraction hypothesis expressed by Einstein, Poincaré, Michelson, and even Lorentz himself. To understand what almost any working scientist feels when he has to evaluate an hypothesis seems to be difficult for those who are not actually engaged in creative scientific work. Hence it will be useful to develop a field that can fairly be called the aesthetics of science. For these matters are still decided in practice on the basis on which Copernicus confessed, apparently so vaguely yet so correctly, to have made his decision against accepting "the planetary theory of Ptolemy and most other astronomers, although consistent with the numerical data": One of his chief objections was that he found their sort of system not "sufficiently pleasing to the mind." Another glimpse of the criterion of choice that is familiar to every working scientist can be found in a letter of Heisenberg to Pauli in which he vented his feelings about Schrödinger's approach to quantum mechanics: "The more I ponder the physical part of Schrödinger's theory, the more disgusting [desto abscheulicher] it appears to me." Schrödinger was no less candid about his feelings concerning Heisenberg's theory when he wrote: "I was frightened away [abgeschreckt], if not repelled [abgestossen], by what appeared to me a rather difficult method of transcendental algebra. . .."129

128 Nor did others think that the contraction hypothesis might not have other uses also. Several, such as the application to the Trouton-Noble experiment, are well known. Others are not. Thus, when F. Hasenöhrl found that this computations yielded a net increase in the temperature of a radiationfilled cavity carried through a closed cycle of velocity under adiabatic conditions, he noted that "our contradiction [with the second law of thermodynamics] is solved when the density of the true radiation does not remain constant. . . The simple assumption is that perhaps the dimensions" are changed by the factor $\left(1-\frac{1}{2} \beta^{2}\right)$, in "complete agreement with the assumption of Lorentz and FitzGerald." F. Hasenöhrl, "Zur Theorie der Strahlungen in bewegten Körpern," Annalen der Physik, 1904, 15: 369. Hasenöhrl also made other uses of the Lorentz-FitzGerald contraction, for example in Sitz. Ak. Wiss. 1907, 116: 1391, and 1908, 117: 207. I thank $\mathrm{S}$. Goldberg for bringing these passages to my attention.

129 Cf. Max Jammer, The Conceptual Development of Quantum Mechanics (New York: McGraw-Hill, 1966), p. 272. Similar criteria guide the personal decision by which a scientist chooses the more probable theory, either when the evidence for and against two theories seems equally balanced or when in fact the evidence seems to be against the theory that is nevertheless preferred. A case of the first kind applies to Galileo, who decided in the Dialogues Concerning the Two Chief World Systems that "it is much more probable that the diurnal motion belongs to the earth alone than to the rest of the universe excepting the earth." A case of the second kind was Einstein's. In the face 
The essential difference between the scientist's use of ad hoc and the logician's is that the former regards it largely as a matter of private science, or science-inthe-making (which may be designated by S-1), whereas the latter regards it as a matter of public science (S-2). It would be wrong to think of (S-1) and (S-2) as always sharply separated, but it is much more erroneous to overlook the deep distinctions between these two meanings of science. In the case at hand they refer to the differences between two legitimate but different uses of "ad hoc" that may be termed ad hoc (S-1) and ad hoc (S-2). For a scientist engaged in original activity, his designation "ad hoc" (or its equivalent terms) is an essentially aesthetic judgment which he makes within (S-1) while he imagines, considers, introduces, or rejects an hypothesis. Ad hoc ( $\mathrm{S}-1)$, in this sense of an act of individual, initially private judgment by a scientist who may very well be deeply and not only rationally involved, differs fundamentally from ad hoc (S-2) in the sense of a public statement with permanent, more or less clear epistemological properties, one that has been published and has become part of scienceas-an-institution. ${ }^{130}$

There is no doubt that an hypothesis that is ad hoc (S-1) has logical properties; the point is that they are not ruling in the actual use of such hypotheses. The scientist who adopts somebody's hypothesis or creates his own for a specific purpose, "in order to account" for a bothersome result or feature of the theory, regards it as ad hoc-not necessarily in a derogatory sense-regardless of its "logical" status. This helps to explain the significance of the passionate and personal "unscientific" language generally used to describe such hypotheses, and incidentally points to gradations of aesthetic or "psychological" acceptability. Thus we have found in the scientific literature characterizations of the following kinds for acceptable ad hoc hypotheses: "not inconceivable," "reasonable," "plausible," "fundamental," "natural," "appealing," "elegant," "likely," "assumed a priori to get the desired results," "auxiliary" or "working hypothesis." On the other hand, when an ad hoc hypothesis is rejected, we see it described in the following way: "artificial," "complex," "contrived," "implausible," "bothersome," "unreasonable," "improbable," “unlikely," "unnecessary," "ugly." Sometimes "ad hoc" itself is applied in the pejorative sense, and then it has such meanings. Or the individual's judgment is transferred to Nature itself, as in the ancient motif which Newton phrased, "Nature is pleased with simplicity, and affects not the pomp of superfluous causes." (Note that in all these cases we do not consider now the quite separate question whether the hypothesis will later turn out to be "right" or "wrong.")

The derogatory characterizations evoke strong behavioral responses, which the

of Kaufmann's apparently authoritative experimental proof of 1906 in favor of Abraham's and Bucherer's theories of electron motion and therefore against Einstein's, the latter in 1907 refused to let the matter be decided by such "facts" and dismissed the rival theories with the judgment: "In my opinion, both theories have a rather small probability, because their fundamental as- sumptions concerning the mass of moving electrons are not explainable in terms of theoretical systems which embrace a greater complex of phenomena." ( $\mathrm{Jb}$. Radioakt., 1907, 4: 28.)

130 I have discussed some differences in the meanings of (S-1) and (S-2) in "On the Duality and Growth of Physical Science," American Scientist, 1953, 41: 89-99. 
author of an ad hoc hypothesis can sometimes foresee and try to ameliorate. Thus in 1892, in the French-language publication which Einstein said he read, Lorentz announced the contraction hypothesis with considerably hedged qualifications: "Now, some such changes in the arms of Michelson's first experiment, and in the dimensions of the slab in the second one, is, so far as I can see, not inconceivable. ... an influence of the order of $\rho^{2}: v^{2}$ is not excluded, and that is precisely what we need."131 And in 1899, writing on the effect of motion on the masses of charged particles, Lorentz said: "Such a hypothesis seems very startling at first sight. Nevertheless, we need not wholly reject it."

The language used when the contraction hypothesis was introduced will give us an important clue to some properties of ad hoc hypotheses which cannot be accommodated in an axiomatic treatment of the theory. Writing on 10 November 1894, Lorentz sent a letter to FitzGerald: "My dear Sir, In his 'Aberration Problems' Prof. Oliver Lodge mentioned a hypothesis which you have imagined in order to account for the negative result of Mr. Michelson's experiment."132 Similarly, when Lodge mentioned the idea of FitzGerald's in public on 27 May 1892 he said, "Professor FitzGerald has suggested a way out of the difficulty by supposing the size of bodies to be a function of their velocity through the ether."133

It is true that the contraction hypothesis, initially so welcome to ether theoreticians because it "explained" the Michelson result, later turned out to be unacceptable because it predicted an unsymmetrical change of dimensions for different inertial systems. But our attention should be fixed on the fact illustrated by these examples that the contraction hypothesis when it was made was clearly and quite blatantly ad hoc-or, if one prefers to use the patois of the laboratory, ingeniously "cooked up," for the narrow purpose which it was to serve. Indeed, in A. M. Bork's article ${ }^{134}$ there are two quotations from Lodge's later reminiscences which provide the plausible setting of a casual chat between Lodge and FitzGerald during which the hypothesis seems to have been first discussed as a nice, wild idea among friends. It is precisely from such situations that some of the finest advances develop-for example, the postulation of the spin of the electron by Goudsmit and Uhlenbeck. ${ }^{135}$ But in the case of this particular hypothesis, it always retained a casual, improbable character, even when Lorentz tried to propose it independently in a somewhat different form, relying lightly on an explanatory scheme based on the presumed analogy between molecular forces

131 H. A. Lorentz, "The Relative Motion of the Earth and the Aether," Verhandelingen der Konink. Akademie van Wetenschappen, Amsterdam, 1892, 1: 74; also in H. A. Lorentz, Collected Papers (The Hague: Martinus Nijhoff, 1937), Vol. IV, pp. 219-223; italics added. Some of these and similar quotations are found in A. M. Bork, "The 'FitzGerald' Contraction," Isis, 1966, 57: 199-207. See also the earlier discussion centering on notes 112 and 113 above.

${ }_{132}$ Draft copy in Algemeen Rijksarchief, The Hague, published by S. G. Brush, in
"Note on the History of the FitzGerald-Lorentz Contraction," Isis, 1967, 58: 231; italics added.

133 O. Lodge, "On the Present State of Knowledge of the Connection Between Ether and Matter: An Historical Summary," Nature, 1892, 46: 164-165; italics added.

134 Bork, "The 'FitzGerald' Contraction," loc. cit.

135 The story is told briefly in Jammer, The Conceptual Development of Quantum Mechanics, pp. 149-150, and at greater length in the sources he cites there. 
(whatever they may be) and electric and magnetic forces. I do not find it at all surprising that FitzGerald himself seems to have been satisfied to let others discuss the hypothesis, that Einstein and others called it ad hoc in a clearly derogatory sense, or that it has traditionally been called the very paradigm of an ad hoc hypothesis.

This working sense of "ad hoc" is not, to be sure, the only meaning of the phrase, but it is one which at this stage of the understanding of hypotheses is the important one for any historical analysis that claims to deal with the actual contribution to science by an individual person. And it is a sense that cannot be dismissed as "merely psychological" or "only psychological." Whether or not epistemological analysis can establish other, perhaps "largely unnoticed," senses for the phrase remains to be seen. C. G. Hempel has shown clearly that "there is, in fact, no precise criterion for ad hoc hypotheses." 136 Then, too, the epistemological distinctions between various meanings of ad hoc hypotheses seem to be more difficult than was once thought; the epistemologist A. Grünbaum's recent analysis that had confidently announced clear distinctions between "logically ad hoc" and "psychologically ad hoc" soon had to be withdrawn by its author, as the result of the demonstration by Hempel that there were serious inadequacies in the work. ${ }^{137}$ One may hope for eventual progress, but one need not wait for it to show the operative sense of ad hoc hypotheses that does exist among scientists. C. C. Gillispie has correctly said: "The special theory of relativity was rather a restriction upon science than an induction from positive phenomena. In his taste for 'inner perfection' in theory, Einstein answered to an aesthetic which logicians of science have not yet reduced to empirical terms, or to inter-subjective agreement." 138

Some questions arise which we should deal with at another occasion at length and here at least cursorily. Are not all hypotheses ad hoc? The answer, in brief, is No. In the special example of the contraction hypothesis, there were alternatives of at least two kinds. One was to explain the negative result of the Michelson experiment by showing that conclusions equivalent to the LorentzFitzGerald contraction could be derived from hypotheses or postulates that were not proposed specifically in order to account for the phenomenon-for example, from Lorentz's transformation equations, although the latter may have initially been completely ad hoc with respect to their own original purpose of proxiding for the invariance of Maxwell's equations. ${ }^{139}$ Indeed, when Lorentz proposed the

136 C. G. Hempel, Philosophy of Natural Science (New York: Prentice Hall, 1966), p. 30.

137 A. Grünbaum, "The Bearing of Philosophy on the History of Science: Philosophical Mastery of the Special Theory of Relativity Is Required for Unraveling its History," Science, 1964, 143: 1406, 1410, 1412.

138 C. C. Gillispie, The Edge of Objectivity (Princeton: Princeton Univ. Press, 1960), p. 516.

139 That the invariance of Maxwell's equa- tions rather than the explanation of ether experiments was the primary motivation for the Lorentz transformation equations is not always granted; e.g., S. J. Prokhovnik in The Logic of Special Relativity (Cambridge: Cambridge Univ. Press, 1967, p. 6) writes: "However, their [Lorentz's and Poincarés] manner of saving the aether concept had a certain artificial character. Their transformation was devised solely to explain a null effect associated with an undetectable medium. It was the shadow of a phantom of zero dimensions." 
transformation equations he had the sense of ad hocness with respect to their purpose; he therefore refused to acknowledge one of the possible consequences of the Lorentz transformation equations, namely a physical meaning of the concept Ortszeit that he felt had been invented for a narrower purpose. The other possibility was to derive a statement whose import would be equivalent to the contraction hypothesis from statements that were even more distant from any specific worry about the Michelson experimental results-for example, from the two basic postulates in Einstein's relativity paper of 1905. This was so simple to do that Einstein, as we saw, did not deign to go through the derivation in his 1905 paper and simply hinted that the reader could derive it for himself for all optical experiments.

The important point here is that "ad hoc" is not an absolute but a relativistic term. Postulates 1 and 2 may be said to have been introduced ad hoc with respect to the relativity theory of 1905 as a whole; Einstein cites little support even for the Vermutung of postulate 1 and virtually nothing to support the Vermutung of postulate 2. But these two principles were not ad hoc with respect to the Michelson experiment, for they were not specifically "imagined in order to account" for its result.

Thus a statement may be ad hoc relative to one context but not ad hoc relative to another. The relativity of ad hocness in this sense is beautifully illustrated by another episode from the history of the FitzGerald proposal itself. As S. G. Brush has shown, ${ }^{140}$ FitzGerald did intend to publish his contraction hypothesis in a letter to the journal Science in 1889, but he never saw a printed copy and thought it had not appeared because the journal stopped publishing at about that time. This initial proposal was entirely ad hoc with respect to the ether-drift experiment:

I would suggest that almost the only hypothesis that can reconcile this opposition [between the Michelson experiment and the Fresnel ether] is that the length of material bodies changes, according as they are moving through the ether or across it, by an amount depending on the square of the ratio of their velocities to that of light. ${ }^{141}$

To add plausibility, he referred to the "not improbable supposition that the molecular forces are affected by the motion, and that the size of a body alters consequently." Rather like Lorentz, FitzGerald based himself here on the qualitative analogy: "we know that electric forces are affected by the motions of the electrified bodies relative to the ether." Later, however, FitzGerald did not seem to regard his proposal any longer as an ad hoc hypothesis, and his reply to Lorentz on 14 November 1894 emphasizes the distinction from the view Lorentz expressed in his own first letter. FitzGerald wrote, "My dear Sir, I have been preaching and lecturing on the doctrine that Michelson's experiment proves, and is one of the only ways of proving, that the length of a body depends on how it is moving through the ether. ... Now that I hear you as an advocate and authority I shall begin to jeer at others for holding any other view." What FitzGerald had pub-

140 "Note on the History of the FitzGeraldLorentz Contraction," op. cit.
$141 \mathrm{G}$. F. FitzGerald, "The Ether and the Earth's Atmosphere," Science, 1889, 13: 390. 
lished in 1889 rather modestly as "almost the only hypothesis that can reconcile this opposition," supported by "a not improbable supposition"-a useful idea, as Lorentz's work showed when he used his own very similar one-had become in 1894 a "doctrine" for FitzGerald, "proved" by the Michelson experiment, and in that context no longer ad hoc. Hence we see "ad hoc" to be a concept that is relativistic in more senses than we may have thought: relativistic for one person with respect to time (ad hoc for FitzGerald in 1889 but not in 1894) and relativistic for different persons at the same time (ad hoc for Lorentz in 1894 but not for FitzGerald in 1894).

How is one to decide whether an hypothesis is ad hoc or not? And, moreover, whether it is repulsively ad hoc or acceptably so? It is here that we connect with Einstein's criterion of the "inner perfection" of the theory. The criterion is the feeling for the "naturalness" or "logical simplicity" of the premises. And we recall again that Einstein makes immediately two points: One is that this point of view "has played an important role in the selection and evaluation of theories since time immemorial," and secondly that "an exact formulation of [it] meets with great difficulties," because "the problem here is not simply one of a kind of enumeration of the logically independent premises (if anything like this were at all unequivocally possible), but that of a kind of reciprocal weighing of incommensurable qualities." 142

As in the pursuit of other aspects of science itself, one's best guide to a decision about the ad hocness of an hypothesis is not logical analysis alone. Here, for better or worse, Einstein's dictum applies: “There is of course no logical way leading to the establishment of a theory, but only groping constructive attempts. ..." Nor is the scientist likely to be much helped by a criterion such as Karl Popper's: “As regards auxiliary hypotheses we decide to lay down the rule that only those are acceptable whose introduction does not diminish the degree of falsifiability or testability of the system in question, but on the contrary, increases it." ${ }^{43}$ Rather, what is required is a feeling for the state of affairs, a Fingerspitzengefühl, which not only distinguishes the quality of insight of different scientists but also forces them to take often quite different views on the same hypothesis. I use the dangerous word "feeling" deliberately, because it indicates accurately the difficult-to-define locus where judgments of the scientific relevance of hypotheses are made. Thus Max Wertheimer recorded Einstein's feeling about Lorentz's contraction hypothesis: "He felt the auxiliary hypothesis to be an hypothesis ad hoc, which did not go to the heart of the matter. . . . He felt the trouble went deeper than the contradiction between Michelson's actual and the expected results." 144

A chief difficulty with the more abstract discussions of the matter which I have seen is that in some cases this essential Fingerspitzengefühl is lacking. In the absence of a firsthand feeling for scientific taste, historical or philosophical scholarship, particularly that directed to a case at the very front of a major scien-

142 “Autobiographical Notes," p. 23.

143 K. Popper, The Logic of Scientific Discovery (New York: Basic Books, 1959), p. 82.
$144 \mathrm{M}$. Wertheimer, Productive Thinking (New York: Harper Brothers, 1945), pp. 173-174. 
tific advance, is endangered because it is likely to be uninterested in or impotent before the personal dimension, the private ( $\mathrm{S}-1$ ) aspect of science, the essential judgment whether or not some approach does "go to the heart of the matter." So-called philosophical mastery must be supplemented by an understanding of matters of scientific taste and feeling. Otherwise it may be brought to bear on an empty case, or worse, one that exists only as a visible model constructed to reflect the maker's own hidden theory of science. It can lead such a person to scold an Einstein for not having behaved like an obedient student in the classroom of a logician, for not having used the "right" terminology, and for not having shouldered an "obligation" to his philosophical masters. ${ }^{51,137}$ It may also lead him to overlook the usefulness of the (partial) definition of an ad hoc hypothesis implied in Newton's exceedingly liberal and permissive Fourth Rule of Reasoning: that an hypothesis is to be accepted as "accurately or very nearly true, notwithstanding any contrary hypotheses that may be imagined," until we have additional evidence by which the hypothesis may be revised or made more accurate. ${ }^{145}$

I suspect that the task of the epistemologist is made difficult because the very nature of his work is different from the necessarily more lax epistemological attitude of the working scientist. Einstein warned of this in a famous passage in the "Reply to Criticisms" which we have cited, where he compares the attitudes of the practitioners of the disciplines and notes that the scientist cannot let himself be "restricted in the construction of his conceptual world by the adherence

145 It is in this spirit that Planck, in "Zur Dynamik bewegter Systeme" (Sitz. Ak. Wiss. 1907, 29: 542-570), argued that one should accept the principle of relativity, since there was nothing as yet which forced one not to accept it as exact. And it is in the same sense that Einstein's first criterion for a good theory asked that "the theory must not contradict empirical facts."

A similar point has been correctly raised in several publications by Michael Polanyi, e.g., in H. Feigl and G. Maxwell, eds., Current Issues in the Philosophy of Science (New York: Holt, Rinehart \& Winston, 1961), pp. 53-55; and also by S. Drake, e.g., in "The Scientific Personality of Galileo" (in press, p. 22 of mimeographed version):

In recent years, I have read many scholarly discussions-I might better say "scholastic" discussions-on the question whether Galileo had any right, as a scientist, to conclude in favor of Copernicus on the basis of the evidence in his possession. ... The crucial point is not whether Galileo had or did not have ocular evidence decisively in favor of Copernicus [by later evidence]; it is how he behaved when he considered that he did have such evidence.

There are, of course, useful discussions of ad hoc hypotheses by philosophers, e.g., by
Mary B. Hesse in Forces and Fields, pp. 226235. She also raises the significant point, not discussed above, that the contraction hypothesis was "somewhat ad hoc because it entailed that motion in the aether is in principle unobservable" (p. 228).

We may take this occasion to remark that an ad hoc hypothesis, in particular a poor one, leaves the feeling that the operations of nature are constricted or restricted by arbitrary human intervention. On the other hand, a large-scale generalization leaves the feeling that it expands the realm of application and shows where the "natural" limits lie: e.g., the first principle of relativity generalizes the equality of inertial systems from mechanics to all of physics. In the same way other major scientific advances are characterized by the positing of an hypothesis that universalizes a limited situation: Newton's proposition of universal gravitation, Galileo's extension of terrestrial physics to celestial phenomena, Maxwell's generalization that abolished divisions between electric, magnetic, and optical phenomena, and others that can be readily supplied from such work as that of Helmholtz, Darwin, and Freud. An early philosophical warrant for this way of hypothesizing was given in Newton's Third Rule of Reasoning. 
to an epistemological system." 146 Hans Reichenbach wisely recognized the danger when he wrote in the same volume a passage we have already touched on:

The physicist who is looking for new discoveries must not be too critical; in the initial stages he is dependent on guessing, and he will find his way only if he is carried along by a certain faith which serves as a directive for his guesses. When I, on a certain occasion, asked Professor Einstein how he found his theory of relativity, he answered that he found it because he was so strongly convinced of the harmony of the universe. No doubt his theory supplies a most successful demonstration of the usefulness of such a conviction. But a creed is not a philosophy; it carries this name only in the popular interpretation of the term. The philosopher of science is not much interested in the thought processes which lead to scientific discoveries; he looks for a logical analysis of the completed theory, including the relationships establishing its validity. That is, he is not interested in the context of discovery, but in the context of justification. ${ }^{147}$

To be sure, scientists on their own side sometimes appear to have mirrorsymmetrical blind spots or lack in interest or preparation. But this need not end in a stalemate. On the contrary, one may hope that further investigations of the status and meaning of ad hocness can benefit from teamwork of the kind that has been so fruitful in scientific research generally-a collaboration among historians, philosophers, scientists, and other scholars who share the conviction that a problem is worth attacking and who are willing to pool their diverse strengths to work on it together.

Returning from this brief excursion into a field that needs further cultivation, we can now refine and summarize our assessment of the probable role of the Michelson experiment in Einstein's work leading to the 1905 paper. In reading Lorentz's book of 1895, Einstein will have found that the experiment was not thought to be the crucial event upon which a new physics must be built: It was only one of several second-order experiments that at the time could be explained only by invoking yet another unhappy ad hoc hypothesis to add to all the others on which current theory was built. Lorentz himself explicitly called the contraction hypothesis a Hülfshypothese and later felt compelled to make an (essentially vain) attempt to explain the Michelson result with more appealing assumptions. Einstein characterized the contraction hypothesis as unsatisfactory on several occasions after 1905. Michelson agreed ("such an hypothesis seemed rather artificial" 148 ). So did Poincaré. So did others who had to face whether or not to work with it. And that is what counts in the characterization of ad hocness.

We conclude that the chief lesson of the Michelson experiment for Einstein was a secondary one: that the then-current contraction explanation of the result of the experiment, by what he felt to be its unappealing ad hoc character, compromised further the ether-committed theory of electrodynamics which Einstein already knew for many other, also largely aesthetic, reasons to be inadequate. The problem Einstein saw was not the logical status of the contraction hypothesis, not Michelson's experimental result itself (for it could be accommodated,

146 Einstein, "Reply to Criticisms," p. 684.

147 Reichenbach, "The Philosophical Sig- nificance of the Theory of Relativity," p. 292; italics supplied.

148 Michelson, Studies in Optics, p. 156. 
even if not "ohne Weiteres"), but the inability of Lorentz's theory to fulfill the criterion of "inner perfection" of a theory.

I have elsewhere drawn attention to the distinctions Einstein made between "constructive theories" and "theories of principle."149 Theories of the latter kind, such as the relativity theory and thermodynamics, start with "empirically observed general properties of phenomena." The accent is not on any one property or phenomenon but on a creative digest or synthesis of "die gesammten Erfahrungstatsachen," the totality of physical experience in a field. It is thus an unhappy caricature to think that any one experiment would be a chief reason for restructuring all of electrodynamics.

This completes our examination of the evidence during the earlier period of Einstein's work. We now turn to the later period, from the 1920's into the 1950's.

\section{Indirect Evidence: After 1905}

First we return briefly to Shankland's interviews to calibrate an endpoint in the long development of Einstein's attitude toward experimentation in general. Thus, Shankland asked Einstein in 1952 about J. L. Synge's recently published approach to relativity which predicted a small positive effect in a Michelson-type experiment. "Einstein stated strongly that he felt Synge's approach could have no significance. He felt that even if Synge devised an experiment and found positive results, this would be completely irrelevant... [Later] he again said that more experiments were not necessary, and results such as Synge might find would be 'irrelevant.' He told me not to do any experiments of this kind." 150

This attitude was characteristic not only at the endpoint. In reading through the documents in the Einstein Archive one finds abundant evidence from the earliest period on that Einstein felt there was a necessity or order in natural law, the perception of which, once he had obtained it even on the basis of the hints furnished by a few chosen experimental facts, allowed him to judge the significance of further experiments. Einstein's responses to the result of D. C. Miller's repetition of the Michelson-Morley experiment is rather typical.

On Christmas Day, 1925, Einstein received a cable from a newspaper service in the United States: "President Miller, American Physical Society, announces the discovery of aether drift. Says 'my work annuls second postulate Einstein theory.' Please cable collect 200-word opinion press rates. . . ." Apparently he gave no answer, but on the same day Einstein wrote to his oldest friend, Michele Besso, "I think that the Miller experiments rest on an error in temperature. I

$149 \mathrm{Cf}$. A. Einstein, "Time, Experience and Gravitation" (1948), in Out of My Later Years (New York: Philosophical Library, 1950). It was discussed in Holton, "Mach, Einstein, and the Search for Reality," pp. 647, 667.

150 Shankland, "Conversations," pp. 53-54; italics added. An experiment along these lines was devised later and gave a null result, as Einstein had predicted. In the same interview Einstein deplored the current state of nuclear theory but again added the same type of caution: "he felt that just the multiplication of facts and experimental data in nuclear physics would not clarify the situation or lead to a final correct theory. This is in marked contrast to the prevalent view that experimental facts will ultimately reveal regularity and thus give the hints that will lead to a theoretical solution. He disagreed completely with this view. .." (ibid., p. 54). 
have not taken them seriously for a minute." Again, on 14 March 1926, in a letter to A. Piccard, Einstein wrote, "I believe that in the case of Miller, the whole spook is caused by temperature influences (air)."151 As it turned out, Einstein's intuitive response was right. In fact it was Shankland and his colleagues ${ }^{152}$ who found in a painstaking and beautiful analysis of Miller's data that the "etherdrift" differences at different altitudes which Miller had reported "were in fact due to the greatly differing temperature conditions in the basement laboratory at Case and at Mt. Wilson."153

We come now to a very significant document that needs to be understood in its setting: the speech given early in 1931 by Einstein on his visit to Pasadena, California, when he came for the first and last time face to face with Michelson. The occasion must have been moving. Michelson, twenty-seven years his senior, was much beloved by Einstein from a distance, as we have noted. Einstein told Shankland he particularly appreciated "Michelson's artistic sense and approach to science, especially his feeling for symmetry and form. Einstein smiled with pleasure as he recalled Michelson's artistic nature-here there was a kindred bond."154

151 Copies of correspondence in the Einstein Archive. Miss Dukas reports that the famous remark "Raffinert ist der Herr Gott, aber boshaft ist Er nicht" was made by Einstein at a reception in 1921 after a lecture in Princeton when Einstein was asked his views about Miller's experiment of 1921 that was reported to have yielded a positive result for the ether drift at higher altitudes.

152 R. S. Shankland, S. W. McCuskey, F. C. Leone, and G. Kuerti, "New Analysis of the Interferometer Observations of Dayton C. Miller," Rev. Mod. Phys., 1955, 27: 167.

153 Shankland, "Conversations," p. 52. There is a significant irony in this story. Shankland's group thought initially that the most likely solution to the puzzle of Miller's results lay elsewhere and invested three years' work in this way. Shankland writes, "it was not until early 1954, after the complete analysis of variance results were available that we were convinced that the periodic effects found by D. C. Miller were not due to statistical fluctuations or his method of analysis. Only then did we plunge deeply into the study of the temperature effects to find the real cause of Miller's results" (ibid., p. 51).

A second irony is that another genial scientist, long before Einstein, had a similar intuitive response about this possible source of error in the Michelson-type experiment. In a recently discovered letter, Michelson, writing to Simon Newcomb from his visit in Berlin on 22 Nov. 1880 about his plans for his very first interferometer experiment, reported the response of the august head of the laboratory, Hermann von Helmholtz: "I had quite a long conversation with Dr. Helm- holtz concerning my proposed method for finding the motion of the earth relative to the ether, and he said he could see no objection to it, except the difficulty of keeping a constant temperature." The letter was first given in Swenson's thesis, "The Ethereal Aether"; see also Shankland, "The MichelsonMorley Experiment," Am. J. Phys., 1964, 32: 19.

Yet another irony lies in Miller's own interpretation of Einstein's interest and response to his work. In a letter from Miller to T. C. Mendenhall of 2 June 1921 Miller wrote, "Last week Prof. Einstein visited me and spent an hour and a half in talking over the ether-drift experiments. I found him exceedingly pleasant and not at all insistent on the theory of relativity, but apparently more interested in the results of the experiments than in anything else and quite willing to accept the results whether for or against the theory. At least he was sincere enough and cordial enough to leave this impression." (From a letter in the Archive of the Center of History and Philosophy of Physics, American Institute of Physics, New York. I thank Dr. Charles Weiner, its Director, for communicating the letter to me.) One plausible explanation of Miller's impression may be contained in Shankland's report on a question he asked Einstein about that visit: "I referred to Einstein's visit to D. C. Miller at Case in 1921. . . . He told me that when he came to the United States that year he did not know a word of English. On the trip he picked up some by ear" (Shankland, "Conversations," p. 50).

154 Shankland, "Conversations," p. 49. 
But Michelson was well known to be no friend of relativity, the destroyer of the ether. Like so many, he was convinced that his own ill-fated experiments were the basis for the theory, and he explained the route in a talk given in 1927: The Michelson experiment had led Lorentz to propose the transformations, and "these contained the gist of the whole relativity theory."155 Einstein reminisced later, "He told me more than once that he did not like the theories that had followed from his work," 156 and he said he was a little sorry that his own work started this "monster."157 Michelson was now seventy-nine years old, weak after a serious stroke that had first forced him to his sickbed two years earlier. The picture taken on that occasion (Fig. 1) shows the frail old man, standing next

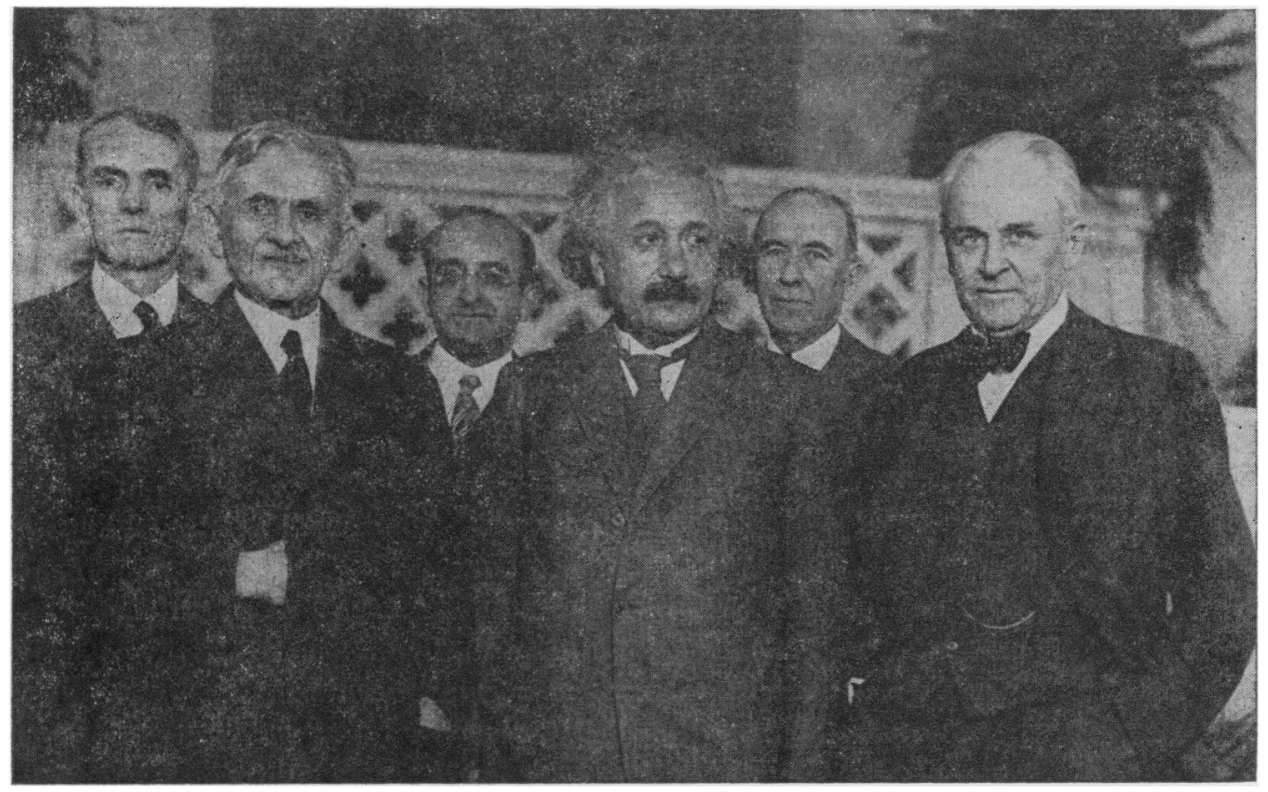

Figure 1. Michelson, Einstein, and Millikan at the California Institute of Technology, winter 1931. (Second row: W. S. Adams, W. Mayer, M. Farrand.) Courtesy Bernard Jaffe and Doubleday \& Co., Inc.

to Einstein, with his usual erect dignity on this last public appearance; but he was marked for the death that came three months later.

Among others present at a grand dinner in the new Athenaeum on 15 January $1931^{158}$ were the physicists and astronomers C. E. St. John, W. W. Campbell, R. A. Millikan, W. S. Adams, R. C. Tolman, G. E. Hale, and E. P. Hubble, as well as Mrs. Einstein and two hundred members of the California Institute Associates. Millikan set the stage with his opinion concerning the characteristic features of modern scientific thought (it takes, "as its starting point, well-authen-

155 Michelson, in "Conference on the Michelson-Morley Experiment," p. 344.

156 Shankland, "Conversations," p. 57. 157 Ibid., p. 56.
158 The proceedings were published in Science, 1931, 73: 375-381. All quotations below are from this source unless otherwise identified. 
ticated, carefully tested experimental facts, no matter whether these facts seem. to fit into any general philosophical theme. . . . In a word, modern science is essentially empirical, and no one has done more to make it so than the theoretical physicist, Albert Einstein"). It is, in fact, largely the same material Millikan republished eighteen years later as part of the introduction to the Einstein issue of the Reviews of Modern Physics. But to the sentence "Thus was born the special theory of relativity" Millikan in 1931 added, "I now wish to introduce the man who laid its experimental foundations, Professor Albert A. Michelson. . .."

Michelson kept his short response in the channel laid out by Millikan:

I consider it particularly fortunate for myself to be able to express to Dr. Einstein my appreciation of the honor and distinction he has conferred upon me for the result which he so generously attributes to the experiments made half a century ago in connection with Professor Morley, and which he is so generous as to acknowledge as being a contribution on the experimental side which led to his famous theory of relativity.

Einstein had not yet responded. Millikan next called on Campbell, representing the splendid group of experimental astronomers present, saying, "I am herewith assigning him the task of sketching the development of the experimental credentials of the general theory of relativity." Campbell recounted the success of the three chief tests, in which the California astronomers had played leading roles.

Millikan then started to introduce Einstein, but prefaced it with a last reinforcement of the philosophical message that had been building up, this time by referring to Millikan's own "experimental verification of predictions" contained in the early papers of Einstein. Seen from his perspective, his evaluation of Einstein's paper on the quantization of light energy (1905) was not surprising: "The extraordinary penetration and boldness which Einstein showed in 1905 in accepting a new group of experimental facts and following them to what seemed to him to be their inevitable consequences, whether they were reasonable or not as gauged by the conceptions prevalent at the time, has never been more strikingly demonstrated."

At last, the stage and the expectations were fully set for Einstein's response. What happened next-or rather, what is supposed to have happened-is widely known from the account given in Jaffe's biography of Michelson:

Einstein made a little speech. Seated near him were Michelson, Millikan, Hale, and other eminent men of science. "I have come among men," began Einstein, "who for many years have been true comrades with me in my labors." Then, turning to the measurer of light, he continued, "You, my honored Dr. Michelson, began with this work when I was only a little youngster, hardly three feet high. It was you who led the physicists into new paths, and through your marvelous experimental work paved the way for the development of the Theory of Relativity. You uncovered an insidious defect in the ether theory of light, as it then existed, and stimulated the ideas of H. A. Lorentz and FitzGerald, out of which the Special Theory of Relativity developed. Without your work this theory would today be scarcely more than an interesting speculation; it was your verifications which first set the theory on a real basis."

Michelson was deeply moved. There could be no higher praise for any man. ${ }^{159}$

159 Jaffe, Michelson and the Speed of Light, pp. 167-168. 
It is the kind of response for which the developing occasion had prepared, and Jaffe gives a natural and clear-cut evaluation of the problem of a possible genetic connection between Michelson's experiment and Einstein's work, one entirely in accord with all the textbook versions we cited earlier: "In 1931, just before the death of Michelson, Einstein publicly attributed his theory to the experiment of Michelson."160

However, reading Jaffe's passage carefully, we need not go so far. Michelson's "stimulating the ideas" of Lorentz and FitzGerald out of which in turn the special theory of relativity "developed" is not a scenario in contradiction with the likely chain of events discussed above: The then-current Lorentz-FitzGerald contraction explanation of the Michelson experiment, as found in the two works of Lorentz (of 1892 and 1895) which we know Einstein had read, by its unappealing ad hoc character compromised further the ether-committed theory of electrodynamics which Einstein already knew for many other reasons to be inadequate. What is missing from Einstein's short response was, to be sure, an elaboration of inputs other than those he was here mentioning; but this clearly was not the occasion to do it.

It is more difficult for us to match the last sentence given above to the ideas we have been developing. As is true for similar remarks at other times, perhaps these too referred to the public acceptance of relativity rather than to Einstein's own developing thoughts leading to his 1905 paper. But the remarks "without your work ... it was your verification ..." more likely would be a personal acknowledgement to Michelson, a public attribution of the kind that Jaffe clearly saw. And in that case, as Kepler put it half-way through the Astronomia nova, "our hypothesis goes up in smoke."

But it turns out that Jaffe's widely read version of Einstein's talk has fallen into the trap of preconceptions that had unwillingly been set up for Einstein. A heading, a little sentence, and a long ending from Einstein's talk that were omitted by Jaffe make a lot of difference. The text of Einstein's talk, in the original German, was published in $1949^{161}$ together with the rather inadequate English translation used in the Science account and, with omissions, in Jaffe's book. The talk starts with "Liebe Freundel"-it is, of course, addressed to the whole company, among whom there were so many whose scientific lives were closely linked to his. And just between Jaffe's last two sentences we find a sentence that switches the discussion away from Michelson and special relativity toward the assembled astronomers and general relativity. The correct passage reads: "You uncovered an insidious defect in the ether theory of light, as it then existed, and stimulated the ideas of $\mathbf{H}$. A. Lorentz and FitzGerald, out of which the special theory of relativity developed. These in turn led the way to the general theory of relativity, and to the theory of gravitation. Without your work this theory would today be scarcely more than an interesting speculation; it was your verifications which first set the theory on a real basis" (italics supplied). Then follows immediately an acknowledgment of each of the experimental contribu- 
tions that had "set the [general] theory on a real basis": those by Campbell, St. John, Adams, and Hubble. ${ }^{162}$

What remains is still a fine compliment to Michelson. Yet even standing before him, and under the accumulated pressures of the dramatic affair, Einstein agreed neither with Millikan's nor with Michelson's version of the genetic connection (nor, of course, with Jaffe's). He did not avail himself of the occasion to say straight out what everyone seemed to have come to hear him say: "Michelson's is the crucial experiment that was the basis for my own work." Rather he seemed to see Michelson as one of the figures on the continuous, long way leading to relativity theory. For even while working on the theory in the spring of 1905 , Einstein claimed that he saw his work not as a violent break with the past, but more modestly, as continuation and improvement of existing trends. ${ }^{163}$

As to the unfortunate omission of the sentence in Jaffe's book, one knows how such things happen, and at the most awkward moment. The significance lies in this: Mistakes of this sort favor the prepared mind. And worse, through no fault of Jaffe's his evaluation has been repeatedly republished by others who, apparently without a scholarly examination of the available original text, found comfort in this evaluation for their purpose of forging a tight genetic link from Michelson to Einstein.

The next document to be examined was published after Einstein's return from Pasadena. It is a summary, in third person, of Einstein's remarks presented on 17 July 1931, to the Physikalische Gesellschaft of Berlin, in memory of Michelson who had died on 9 May 1931. Once more, the chance offered itself to Einstein to say what all textbooks had long been saying, and to do so under the most natural circumstances. But, as at Pasadena, this did not happen. Einstein is reported to have said (without direct attribution) that Michelson's greatest idea "was the invention of his famous interference apparatus, which came to be of greater significance both for relativity theory as well as for the observation of spectral lines," and "this negative result [of the Michelson experiment] greatly

162 The English translations published by Science (1931) and Proc. Am. Phil. Soc. (1949) differ only slightly. But for the sake of completeness I shall give here a more faithful translation of the first part of the German-language text (n. 161):

Dear friends! From far away I have come to you, not to strangers but to men who for many years have been faithful comrades in my work. You, my honored Herr Michelson, began when I was only a small boy, not even a meter high. It was you who led the physicists into new paths, and through your marvelous experimental labors prepared for the development of the relativity theory. You uncovered a dangerous weakness in the ether theory of light as it then existed, and stimulated the thoughts of H. A. Lorentz and FitzGerald from which the special theory of relativity emerged. This latter, in turn, led the way to the general theory of relativity and to the theory of gravitation. Without your work this theory would today be scarcely more than an interesting speculation; your verifications furnished the real [or realistic] basis for this theory. Campbell's determination of light deflection of light rays passing the sun; St. John's determination of the red shift of spectral lines through the gravitational potential that exists at the sun's surface; . . .

163 As he wrote to his friend Conrad Habicht about the relativity paper: "The fourth work lies at hand in draft form, and is an electrodynamics of moving bodies, making use of a modification of the theory of space and time." In Carl Seelig, Albert Einstein (Zürich: Europa Verlag, 1954), p. 89; see also p. 97; italics supplied. 
advanced the belief in the validity of the general relativity theory." 164 The best phrase casts some doubt on the accuracy of the report, since the Michelson experiment could be interpreted by the special rather than the general theory. But even in this dubious form the report is most consistent with Einstein's earlier statements pointing out the usefulness of the experiment in convincing other physicists of the value of relativity theory.

There ensued a lull for some years during which the question of a possible debt to Michelson was apparently not raised. Then, in a letter of reply on 17 March 1942 to Jaffe, Einstein again had to make a statement on the matter. It has most of the characteristics of the replies to Shankland eight to twelve years later, that is, the influence would have been to strengthen a previously obtained conviction and to remove doubts (on the part of others?):

It is no doubt that Michelson's experiment was of considerable influence upon my work insofar as it strengthened my conviction concerning the validity of the principle of the special theory of relativity. On the other side I was pretty much convinced of the validity of the principle before I did know this experiment and its results. In any case, Michelson's experiment removed practically any doubt about the validity of the principle in optics, and showed that a profound change of the basic concepts of physics was inevitable. ${ }^{165}$

In 1946 Einstein wrote at Schilpp's request the "Autobiographical Notes," from which we have already quoted all sections relevant to the question before us. It has often been remarked, particularly by those who believe in the "missing link," that they found it "frustrating" that even on that occasion Einstein did not provide what they so desired. But he mentioned neither the name nor the experiment.

From 1950 on, for the remaining five years of Einstein's life, the question somehow began to be asked much more frequently than ever before. The various requests fall during the period of Shankland's interviews, which we have already mined, and the answers overlap on the whole quite consistently with them.

On 8 July 1953 Einstein was interviewed by the physicist N. Balazs, whose account was then published by M. Polanyi in 1958. Balazs reported:

... The Michelson-Morley experiment had no role in the foundation of the theory. He got acquainted with it while reading Lorentz's paper about the theory of this experiment (he of course does not remember exactly when, though prior to his papers), but it had no further influence on Einstein's considerations and the theory of relativity was not founded to explain its outcome at all. 166

164 "Gedenkworte auf Albert A. Michelson," Zeitschrift für angewandte Chemie, 1931, 44: 685.

165 B. Jaffe, Men of Science in America (New York: Simon \& Schuster, 1944), p. 372. Also reprinted in Jaffe, Michelson and the Speed of Light, pp. 100-101. The same implication without further illumination is found in the well-known and slightly breathless book by the psychologist Max Wertheimer, Productive Thinking. Wertheimer reports that from 1916 on he spent "hours and hours" with Einstein, "to hear from him the story of the dramatic developments which culminated in the theory of relativity" (p. 168). "When Einstein read about these crucial experiments made by physicists, and the finest ones made by Michelson, their results were no surprise to him, although very important and decisive. They seemed to confirm rather than to undermine his ideas" (p. 172).

166 In M. Polanyi, Personal Knowledge (Chicago: Univ. Chicago Press, 1958), p. 11. 
Polanyi, a prominent physical chemist and long-term acquaintance of Einstein's, also published a second statement, "approved for publication by Einstein early in 1954": "The Michelson-Morley experiment had a negligible effect on the discovery of relativity." 167

At about the same time the pious duty fell on Einstein to acknowledge a debt to one of his foremost heroes and mentors. This was done in the short essay "H. A. Lorentz als Schöpfer und als Persönlichkeit," dated 27 February 1953 and composed for delivery at Leyden that year during the commemoration of the centenary of Lorentz's birth. ${ }^{168}$ After a fine tribute to Lorentz's leadership and eminence in physics at the turn of the century, Einstein gives a (partial) list of chief hypotheses on which Lorentz had based his reconstruction of electrodynamics, adding, "It is a work of such consistency, lucidity, and beauty as has only rarely been attained in an empirical science."

But this empirically based, constructive theory has its limits, and in describing them Einstein points out two quite different features of electrodynamics around the turn of the century which, he implies, set the stage for Einsteinian relativity theory. One of these is primarily aesthetic:

To him [Lorentz], Maxwell's equations in empty space held only for a particular coordinate system distinguished from all other coordinate systems by its state of rest. This was a truly paradoxical situation because the theory seemed to restrict the inertial system more strongly than did classical mechanics. This circumstance, which from the empirical point of view appeared completely unmotivated, was bound to lead to the theory of special relativity.

This remark is entirely consistent with the long tradition that the primary impetus for Einstein was the essential requirement of finding symmetry and universality in the operations of nature.

The other problem with Lorentz's theory to which Einstein draws attention in the essay concerns the experimental side: the inability of the theory to encompass all the relevant phenomena in an elegant manner. In the half-paragraph devoted to this failure Einstein sketches a severely abbreviated version of the state of affairs around the turn of the century, far less adequate than Lorentz's own confession. Instead of listing all the awkward experiments treated in Lorentz's Versuch of 1895 or the larger number available by 1905, Einstein mentions only the one for which Lorentz, with FitzGerald, had fashioned the famous saving hypothesis of contraction, namely the Michelson experiment; and then Einstein adds two more sentences, more obscure than most others we have now read on this topic and seemingly more at variance with them:

167 Ibid., p. 10. Polanyi goes on to use these statements to support his own conclusions:

The usual textbook account of relativity as a theoretical response to the MichelsonMorley experiment is an invention. It is the product of a philosophical prejudice. When Einstein discovered rationality in nature, unaided by any observation that had not been available for at least 50 years before, our positivistic textbooks promptly covered up the scandal by an appropriately embellished account of his discovery.

This remark led to remarkably vituperative attacks upon him from the extreme positivistic school. The ensuing debate was revealing in its own right, but its examination must be delayed to another occasion.

168 Translation in A. Einstein, Ideas and Opinions, pp. 73-76, under the title "H. A. Lorentz, Creator and Personality." 
The only phenomenon whose explanation in this manner did not succeed fully, - that is, without additional assumptions-was the famous Michelson-Morley experiment. That this experiment led [or brought, or guided; hinführte] to the special relativity theory would have been inconceivable without the localization of the electromagnetic field in empty space. Indeed, the essential step was in any case the tracing back [of the phenomenon?] to Maxwell's equations in empty space or-as one called it then-in the aether. ${ }^{169}$

The middle sentence is, of course, of particular interest to us here; but its doubly negative and rather obscure construction gives us no warrant to change it to some other statement such as "The experiment led me to the special relativity theory." During nearly fifty years of responding on this question, Einstein had shown no hesitation to use the first person singular when he wished to; and whenever he did so, he coupled the reminiscence of his own progress and the experiment by saying at most, as in the reply to Jaffe in 1942, the experiment "was of considerable influence upon my work insofar as it strengthened my conviction concerning the validity of the principle of the special theory of relativity."

It seems to me closest to Einstein's intention that in the passage for Lorentz's memorial celebration he wanted to provide a brief indication of an experimental counterpart to the aesthetic-theoretical guidelines we noted a little earlier, and that he hit upon the most frequently used experimental illustration for the purpose of all didactic expositions (including Einstein's own ${ }^{170}$ ). We learned earlier that when Einstein wrote in the passive voice in answering questions or obligations he spoke of the importance the Michelson experiment had for the further development and acceptance of the theory by other physicists. When he mentioned the influence of the experiment on himself explicitly and in first person, he said the effect was "negligible," "indirect," "rather indirect," "not decisive," or at most "considerable" in the limited sense of the reply to Jaffe. We have therefore learned to distinguish between Einstein's evaluations of the effects on public science and on private science.

These considerations lead directly to the last document in this case, the last of the replies of Einstein, given about a year before his death. On 2 February 1954 F. G. Davenport of the Department of History of Monmouth College, Illinois, wrote to Einstein that in connection with a study on "Scientific Interests in Illinois 1865-1900" he was looking into evidence that Michelson had "influenced your thinking and perhaps helped you to work out your theory of relativity."

169 As is not unusual, one cannot rely on published translations; we established the text by using the German original in the Einstein Archive:

Das einzige Phänomen, dessen Erklärung auf diesem Wege nicht restlos, d.h. nicht ohne zusätzliche Annahmen, gelang war das berühmte Michelson-Morley-Experiment. Dass dies Experiment zu der speziellen Relativitätstheorie hinführte, wäre ohne die Lokalisierung des elektromagnetischen Feldes im leeren Raume undenkbar gewesen. Der wesentliche Schritt war eben überhaupt die Zurückführung auf die Maxwell'schen Gleichungen im leeren Raume oder-wie man damals sagte-im Aether.

Two other translations that differ slightly from each other are given in Ideas and Opinions, p. 75, and in the collection $H$. A. Lorentz: Impressions of his Life and Work, ed. G. L. DeHaas-Lorentz (Amsterdam: North Holland Publishing Co., 1957), p. 8.

170 See notes 29 and 30 above. 
Not being a scientist, he asked for "a brief statement in non-technical terms, indicating how Michelson helped to pave the way, if he did, for your theory."

In a hitherto unpublished letter, ${ }^{171}$ Einstein answered very soon after receipt, on 9 February 1954. Perhaps having benefited from the repeated questions during the previous few years and by having pondered again over his answers, he now seemed very willing to respond in detail to a stranger and to offer the letter for publication, as well as to invite continued correspondence. It is a thoughtfully composed reply which we can let stand by itself as the summation of what we have learned from other documents-including the need to differentiate sharply between the effect of the experiment on the development of physics and its effect on the development of Einstein's own thought, between the beauty of the immortal experiment and its subsidiary place in theory, between the statements a scientist may make in direct response to repeated questions and the statements he volunteers (in the latter case Einstein preferred not to speak about specific experiments except Fizeau's and the aberration experiments), and between the large interest the whole question has held for many people and the small interest it seemed to have held for Einstein.

Dear Mr. Davenport:

Before Michelson's work it was already known that within the limits of the precision of the experiments there was no influence of the state of motion of the coordinate system on the phenomena, resp. their laws. H. A. Lorentz has shown that this can be understood on the basis of his formulation of Maxwell's theory for all cases where the second power of the velocity of the system could be neglected (effects of the first order).

According to the status of the theory, it was, however, natural to expect that this independence would not hold for effects of second and higher orders. To have shown that such expected effect of the second order was de facto absent in one decisive case was Michelson's greatest merit. This work of Michelson, equally great through the bold and clear formulation of the problem as through the ingenious way by which he reached the very great required precision of measurement, is his immortal contribution to scientific knowledge. This contribution was a new strong argument for the non-existence of "absolute motion," resp. the principle of special relativity which, since Newton, was never doubted in Mechanics but seemed incompatible with electro-dynamics.

In my own development Michelson's result has not had a considerable influence. I even do not remember if I knew of it at all when I wrote my first paper on the subject (1905). The explanation is that I was, for general reasons, firmly convinced how this could be reconciled with our knowledge of electro-dynamics. One can therefore understand why in my personal struggle Michelson's experiment played no role or at least no decisive role.

You have my permission to quote this letter. I am also willing to give you further explanations if required.

Sincerely yours, Albert EINSTEIN.

But if he truly felt this way, why did Einstein not make any voluntary statements to stop the myth he must have seen spreading all around him? Many opportunities offered themselves. Why did he wait for interrogators such as

171 Copy in the Einstein Archive, Princeton. 
Jaffe, Balazs, Shankland, Polanyi, and Davenport to raise the issue before denying what almost everyone else seemed to be affirming? The answer, of course, can be found in Einstein's general pattern of response. It would have been most uncharacteristic for Einstein to take pen in hand to attack a myth of this kind. Even on the purely scientific issues he only very rarely published a correction of (not to speak of an attack on) the many erroneous interpretations of his work, and it is even less conceivable that he would, of his own will, publish anything that would seem to increase the degree of originality of his own work or imply a diminished status of another scientist. It is also relevant that he tolerated even the most vicious printed attacks on his work and person by Nazi scientists (and nonscientists) with astonishing humor.

In fact, from the point of view of the historian, Einstein's characteristic fault was to be too tolerant. A notable episode will illustrate the point. When E. Whittaker was composing his second volume of A History of the Theories of Aether and Electricity (1953), in which he explicitly ascribes the chief original work on special relativity to Lorentz and Poincaré, Einstein's old friend Max Born, then in Edinburgh, saw Whittaker's manuscript. Having seen the rise of relativity practically from its beginning, Born was astonished and somewhat angry about this misleading version. He wrote to Einstein in dismay that Whittaker had persisted in the plan to publish his version despite the contrary evidence which Born had submitted (including translations from the German originals of some relevant articles he had prepared for Whittaker). Though Einstein was probably somewhat wounded, he wrote on 12 October 1953 to reassure Born:

Don't give any thought to your friend's book. Everyone behaves as seems to him right, or, expressed in deterministic language, as he has to. If he convinces others, that's their problem. At any rate, I found satisfaction in my efforts, and I don't think it is sensible business to defend my few results as "property," like an old miser who has laboriously gathered a few coins for himself. I don't think ill of him. . . . And I don't have to read the thing. ${ }^{172}$

\section{Concluding Remarks}

Historians are quite used to the large discrepancy we find here between documentable history of science on the one hand and, on the other, the popular history found in texts and in the writings of eminent scientists and some philosophical analysts. Putting together all extant firsthand documents-including the 1905 paper, the Shankland interviews, the "Autobiographical Notes," and the letters-we see they fit together and tell a story for which the secondary sources had not prepared us. It is a scenario of which we cannot, in the nature of the case, be absolutely certain, but one which is highly probable. Indeed, the role of the Michelson experiment in the genesis of Einstein's theory appears to have been so small and indirect that one may speculate that it would have made no difference to Einstein's work if the experiment had never been made at all. To be sure, the public acceptance of the theory might well have been delayed; but through his reading in Lorentz's works, Einstein in 1905 had

172 Copy in the Einstein Archive. 
available enough other "unsuccessful attempts to discover any motion of the earth relatively to the "light medium," and enough other evidences of what Lorentz himself called a "clumsiness" in the then-current theory.

This special case may yield some more widely applicable conclusions. Above all, it forces us to ask anew what are the most appropriate styles and functions of historical scholarship today. On this point, Einstein's own opinion is illuminating. Shankland had asked Einstein during their first conversation in 1950 whether "he felt that writing out the history of the Michelson-Morley experiment would be worthwhile":

He said, "Yes, by all means, but you must write it as Mach wrote his Science of Mechanics." Then he gave me his ideas on historical writing of science. "Nearly all historians of science are philologists and do not comprehend what physicists were aiming at, how they thought and wrestled with their problems. Even most of the work on Galileo is poorly done." A means of writing must be found which conveys the thought processes that lead to discoveries. Physicists have been of little help in this, because most of them have no "historical sense." Mach's Science of Mechanics, however, he considered one of the truly great books and a model for scientific historical writing. He said, "Mach did not know the real facts of how the early workers considered their problems," but Einstein felt that Mach had sufficient insight so that what he said is very likely correct anyway. The struggle with their problems, their trying everything to find a solution which came at last often by very indirect means, is the correct picture. ${ }^{173}$

In discussing the approach of "nearly all historians" (perhaps somewhat too brusquely) Einstein accentuates the need to deal with the private phase of scientific effort-how a man thinks and wrestles with a problem. In discussing the physicists themselves (perhaps also too brusquely) Einstein accentuates the need for a particular kind of historical sense, one that largely intuits how a scientist may have proceeded, even in the absence of "the real facts" about the creative phase. It is a challenging statement, a recommendation to adopt for research in the history of science a lesson Einstein had learned from his research in physics: Just as in doing physics itself, Einstein here advises the historian of science to leap across the unavoidable gap between the necessarily too limited "facts" and the mental construct that must be formed to handle the facts. And in such an historical study, as in physics itself, the solution comes often "by very indirect means"; the best outcome that can be hoped for is not certainty but only a good probability of being "correct anyway."

One can well agree with this call for new ways of writing about the thought processes that lead to major discoveries, without having to agree at this late date with the particular model of Mach's Science of Mechanics. The most obvious difficulty with following Einstein's advice is of course the unspecifiability of "sufficient insight." Another is that any study of the processes of discovery-that evanescent, partly unconscious, unobserved, unverbalized activity-is by definition going to yield a report with apparently vague and contradictory elements. Yet another is that the invitation to leap courageously may cause the historian to

173 Shankland, "Conversations," p. 50. 
slight even some of the most pertinent and easily available documents. And a fourth trouble is that there are some problems which now seem largely unsolvable by any method and may remain so for a long time: the problem of genius, of reasons for thematic and aesthetic choices, of interaction between private and public science, not to speak of the problem of induction.

Ernst Mach himself would perhaps have objected to Einstein's characterization of his work on the history of science, laudatory though it was intended to be. But Einstein was right nevertheless in ascribing to Mach, and recommending to others, an unconventional method, despite the difficulties and dangers it may pose. For in this way one can at least hope to penetrate beyond the more pedestrian or trivial aspects of an historic case of such magnitude, to recognize more fully the feat of intellectual daring and superb taste that was needed to create the theory.

Of course, experiments are essential for the progress of science. Of course, the chain from a puzzling new experiment to a theoretical scheme that explains it is the more usual process, particularly in the everyday work of most scientists. Of course, experiments influenced the developing thought processes of the young Einstein struggling with the problem of understanding electrodynamics in a new way, to get at the "heart of the matter." Of course, Michelson's experiment played an indirect role in this, if only because Einstein found Lorentz's theory of electrodynamics to be inadequate precisely because "it was leading to an interpretation of the result of the Michelson-Morley experiment which seemed to me artificial," as Einstein wrote in the Michelson centenary message, or as too patently "ad hoc," as he wrote on other occasions.

Yet, the experimenticist fallacy of imposing a logical sequence must be resisted. Not only is it false to the actual historic development of thought processes that may have led to major scientific discoveries; not only might the doctrine inhibit creative work in science if it were taken too seriously; but also, by drawing attention primarily to the externally visible clay that provides factual support and operational usefulness for the developed theory, it does not do adequate justice to the full grandeur of the theory. The basic achievement of Einstein's theory was not to preserve hallowed traditional conceptions or mechanisms; it was not to produce a logically and tightly structured sequence of thoughts; it was not to build on a beautiful and pedagogically persuasive experiment. Rather, the basic achievement of the theory was that even at the cost of sacrificing all these, it gave us a new unity in the understanding of nature. 